\title{
Literature Review of the Status of Research on the Transportation and Mobility Needs of Older Women
}


This publication is distributed by the U.S. Department of Transportation, National Highway Traffic Safety Administration, in the interest of information exchange. The opinions, findings and conclusions expressed in this publication are those of the author(s) and not necessarily those of the Department of Transportation or the National Highway Traffic Safety Administration. The United States Government assumes no liability for its contents or use thereof. If trade or manufacturer's name or products are mentioned, it is because they are considered essential to the object of the publication and should not be construed as an endorsement. The United States Government does not endorse products or manufacturers. 


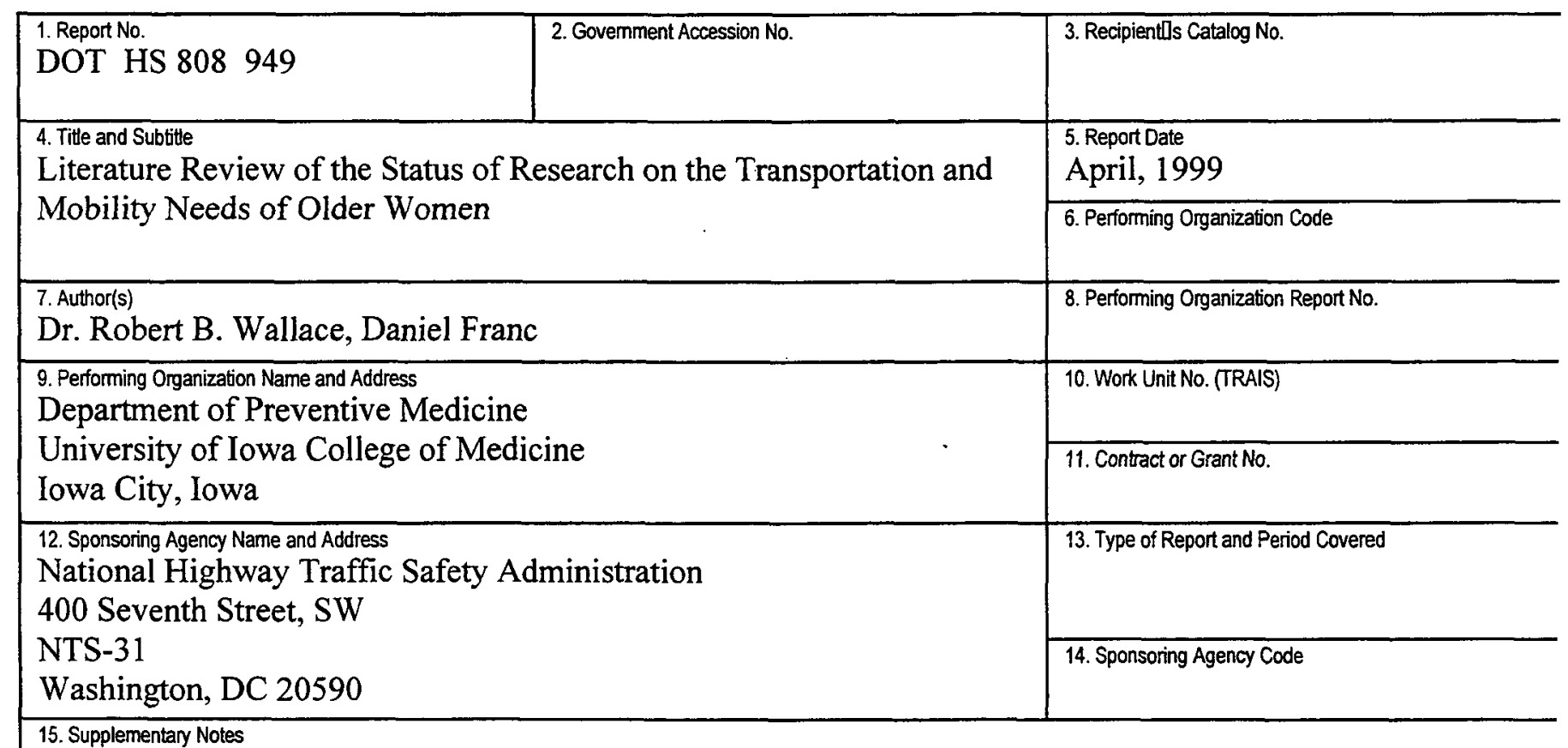

16. Abstract

The overall goal of this report is to review the existing literature related to the safe mobility of older women and to make recommendations with respect to future research and data collection on safe mobility and transportation needs. The number of older women will increase substantially in the next few decades, and while age-specific physical disability rates may be lower, the number with disabilities that have an impact on mobility and transportation needs will increase. Family and other social support networks will likely decline in the future because of smaller families and more single and divorced persons. Current transportation and gerontological surveys offer useful information but are inadequate for the broad range of issues at hand.

In order to develop policies that promote safe mobility for older women, a number of targeted research areas need development or enhancement, including: a) development of population surveys that attend to multiple issues including transportation practices, mobility needs and desires, economic status and perceptions of the safety and acceptability of current transportation modes; b) development and validation of measures of physical disability that more accurately reflect the use of various transportation modes; c) study of economic status and access to transportation; d) specific study of disabled middle-aged populations now becoming older; e) monitoring of trends in urban and regional design relevant to safe mobility of older women, including new forms of housing such as sheltered and assisted living facilities; and f) improvement of forecasting techniques to predict future mobility and transportation needs including social, economic and physical disability factors.

\begin{tabular}{|l|l|l|l|l|}
\hline $\begin{array}{l}\text { 17. Key Words } \\
\text { older driver, older women, transportation, } \\
\text { mobility, gerontological surveys }\end{array}$ & \multicolumn{3}{|c|}{ 18. Distribution Statement } \\
\hline \multicolumn{2}{|c|}{} & 20. Security Classif. (of this page) & \multicolumn{3}{|c|}{ 21. No. of Pages } & 88 & 22. Price \\
\hline 19. Security Classif. (of this report) & & & \\
\hline
\end{tabular}




\section{Executive Summary}

The Department of Preventive Medicine of the University of Iowa College of Medicine was contracted to prepare a document addressing the research needs for maintaining the safe mobility of older women in the United States, with an emphasis of automobile driving as well as other modes of transportation. This activity was funded by a grant from the National Safety

Council. The specific objectives were:

1. Through epidemiological databases, other databases, and literature sources, review current population health, function, socio-economic, and mobility and driving status of American women aged 65 and over and consider the issues in projecting future population function and mobility status.

2. Identify existing data sets that summarize current transportation use, both public and private, in older women as defined in Objective 1. The relative availability of various modes shall be discussed, and their suitability for individuals with various functional decrements should be discussed.

3. Summarize the existing literature on the relation of functional status of older women and the use of available transportation modalities, and the suitability of those options in relation to functional status.

4. Review the relationships between changing family size, socio-economic status, and inter-generational resource exchanges with respect to access to transportation among older women.

5. Make recommendations for future research needs, based on knowledge gaps identified in meeting Objectives 1-4.

Review of the available literature and selective consultation with non-published sources and relevant investigators were undertaken, and a few major databases were analyzed to provide the information in the report. A population approach to assessing the information summarized here was taken. That is, emphasis was placed on geographically-referent studies and surveys over the larger volume of important organizational, social, transportation and clinical research that employed small, selected samples of persons for study. The lack of critical population research in many relevant areas made addressing some of research questions difficult and tentative, relegating them to becoming part of the research agenda, summarized below. 
Major conclusions from evidence are as follows:

- The number of older women in the United States will continue to increase at a substantial rate, both due to increased survivorship, immigration and the larger size of younger cohorts.

- Currently, about 20 percent of American women over age 65 years do not operate an automobile, both for reasons of quitting motor vehicle operation and because of never having been a driver. However, in successive cohorts of older women, a greater proportion will be motor vehicle operators, at least at some point in their lives, as is true of men.

- There is confusion in the gerontological and geriatric literature on the difference between disability and mobility. Most population data on the health and function of older women emphasize disability as a set of physical movement disorders often related to medical conditions, rather than mobility, the ability to move from one place to another to achieve social and recreational ends. While there is substantial information on disability rates among older women, there is very little population-based information on the status of mobility and transportation, nor were published projections for the next few decades identified.

- Older women, as older men, continue to depend heavily on the automobile for transportation, and based on federal surveys, that is increasing. Over the past decade, the use of public transportation has declined marginally. Walking to achieve mobility has also declined. The reasons for these changes have not been systematically evaluated, although 
focus groups as well as qualitative and "clinical" research have suggested some important reasons.

- With the increase in the number of older women, there are also contradictory trends that will make projecting motor vehicle operating patterns and transportation needs extremely difficult. For example, tomorrow's older women will have smaller families with fewer children to provide social and transportation support, aided by high divorce rates among today's younger and middle-aged women. On an age-specific basis, they will likely be more healthy than today's cohorts, but living longer will lead to more late-onset physical and cognitive disability, leading to substantial challenges in sustaining safe mobility. On the other hand, older women will be more educated and at least a portion will be more affluent, fostering self-sufficiency. Assessing future trends in availability of safe, acceptable public transportation and urban and regional design, as well as assistance in mobility for those with overt handicaps is most difficult. There are also particular problems in transportation access for rural women. On the balance, these complex and divergent trends make projection of the net effect on mobility needs for the next generation complex.

- A large number of recent and concurrent national surveys with information relevant to the safe mobility of older American women. Many offer important segments of the research information needed for policy and planning, but all are deficient in elements of content necessary for a comprehensive approach to this issue. Other types of informative research were reviewed and deficient content areas were also noted. 
The report concludes with research recommendations based on the review of the scientific evidence and ancillary consultations and communications. In general these recommendations call for more targeted research in the following areas:

- Population surveys should be expanded in content in order to provide a sufficient breadth in areas such as personal social goals, priority mobility needs and access to and perceptions of all common varieties of public and private transportation, as well as evaluating current usage of transportation.

- Measures of physical and cognitive disability used in population survey research should be further developed and validated to more accurately reflect older women's abilities to use various kinds of public transportation as well as personal motor vehicles.

- Special attention needs to be paid to the increasing cohorts of young and middle-aged persons who were disabled at an earlier age and are now approaching older ages because of advances in health care and rehabilitation. Their mobility needs and transportation modes may be different in a variety of important ways.

- Research should be conducted on the relation of personal and family wealth and assets to transportation access. Economic factors seem to be important for at least a quarter of the population and these factors need to be better understood if safe mobility for the entire population is a goal.

- Demographic projection and forecasting techniques should be enhanced to define for the next few decades not only the population size and survivorship of older women, but also family and social network size and availability, the levels of transportation-related disability and economic access to personal and public transportation. 
- Additional targeted research is needed on the personal perceptions of older women with respect to access, acceptability and utility of all modes of transportation and other sources of mobility, as well as personal mobility needs and desires, in order to more effectively plan for mobility needs.

- More study is needed on the evolution of urban and regional designs that affect the mobility of older women. Changes that promote safe mobility should be championed. Also, the impact of assisted living facilities and other newer modes of residential design for older persons in general and older women in particular should be evaluated for their impact on transportation needs. 
(25May99)

Literature Review of the Status of Research on the Transportation and Mobility Needs of Older Women

Prepared for the National Safety Council and the National Highway Traffic Safety Administration

Robert B. Wallace, MD, MSc

Daniel Franc, BS

Department of Preventive Medicine

University of Iowa College of Medicine 


\section{Introduction}

The overall purpose of this report is to review the status of transportation and mobility research concerning older women in the United States. Some research is drawn from other countries, mostly in western Europe, but the intent is to understand the domestic situation, which usually will be based on domestic investigations. Studies on health, transportation and automobile driving are often not in the formal, peer-reviewed medical literature, and thus we sought conference reports and consulted prominent investigators and research program directors in this area, but it is not likely that the entirety of the relevant literature was found. In addition, while there are several population surveys that offer considerable insight into the issues at hand, some have become dated and decreasingly relevant only because there are important long-term and sometimes rapidly changing trends in the use of transportation and motor vehicles among older women. These trends require forecasting techniques to determine some of the issues for the next several decades, which is hazardous and uncertain at best, and not a substitute for continual data collection to assess the actual situation among older women. While the automobile dominates transportation utilization for most Americans, older and younger, male and female, we have tried to review some of the less robust literature on other modes of transportation. Some of the tables provided here are from unpublished data of the reports' authors, and that will be specifically noted.

The final "product" of this report will offer suggestions for encompassing surveys that have sufficient breadth of content to more fully assess the older women's transportation issues. The language of this report will be aimed at the educated lay person, and to the best of our ability we have eliminated as much jargon as possible from 
the text. In some places it will be unavoidable, and the next section of this report will deal with some of the vocabulary and definitional issues.

\section{Some Definitional and Conceptual Issues Related to Transportation and Mobility}

While mobility and transportation issues form the major substance of this report, an introduction on the basic definitions of mobility and disability, and relevant conceptual issues from the health and gerontology literature is of value:

\section{A. Mobility}

The term "mobility" has at least two uses in the literature. In the rather voluminous literature on disability and dysfunction among older persons, the term is most often used to indicate ambulation or other lower extremity activities such as transferring from a bed to a chair within a room, walking across a room, climbing stairs, jogging, moving furniture, and so on. Very little of the epidemiological literature on women's mobility actually deals with the other meaning central to this report: the ability to move from one place to another for purposes of meeting personal, social, employment or recreational needs and desires. This may involve walking, with or without assistance, or it may involve some form of transportation. The latter is uncommonly addressed in the literature, and this is one of the general data needs for understanding disability and mobility among older American women.

\section{B. Disability}

The medical, epidemiological and demographic literature also uses the term disability in at least two different ways. One definition, preferred here and in keeping with World Health Organization (WHO) nomenclature (World Health 
Organization, 1993), refers to disabilities as (physiological) abnormalities in the function of limbs or other body parts due to illnesses or anatomic abnormalities. Such functions might include grasping an object, standing upright or walking, reaching upward or kneeling and stooping. This is not the same as mobility, but might be important for achieving mobility. The term disability, also sometimes called "dysfunction" in the health literature, also has been used to refer to inability to carry out important functions such as dialing a telephone, attending an educational function, traveling to another place for shopping, visiting a physician or similar need, or attending religious or recreational activities. Indeed, many aspects of automobile driving could be included here. However, the WHO refers to deficits in these latter activities as handicaps, since there is considerable complexity because they occur in a social context (Edwards, 1997). It is this social context that is most crucial to assessing transportation and mobility needs, and that is why we prefer the WHO terminology.

\section{Transportation}

We consider transportation to be the commonly available modes of movement of persons from one place to another. This includes all forms of public transportation, either intended for the general public or for those with certain needs, such as those with physical disabilities. Several types of transportation will not be included, either because they are rare in the United States, because they meet very specific needs or because they are used within a house or apartment. Thus, among the exclusions would be monorails, helicopters, pedicabs, wheelchairs (motorized or non-motorized), robotic devices assisting 
human movement, motorized walkways, and elevators, escalators or other conveyances that move persons within a single building. This is not to diminish the importance of such currently available or future inventions or innovations, but only to note that this report will be limited to ground transportation between places where the distance usually is measured in miles, including inner city travel.

Given the dominance of automobile driving in the United States, much of this report will focus on the auto as a source of mobility for older women. It should be pointed out here, however, that in general, motor vehicle operation implies successful operation, which assumes safe operation without increased crash risk. In fact, all forms of transportation have safety issues and concerns that should be addressed.

\section{The Environment in Which Mobility, Disability and Transportation}

\section{Occur}

The environmental context in which mobility, disability and transportation occur is critical to considering these issues in older women. For example, the personal desires and preferences of older women are central to understanding their transportation and mobility needs. These can vary greatly from one person to another, and are subject in part to access to public information, advertising and the advice and counsel of friends, family and various professionals. Personal preferences are altered as environmental opportunities and information change, so these would need to be surveyed at regular intervals. An example from information technology is the ability to shop for many items and conduct banking functions on the Internet, decreasing the need for physical transportation or 
perhaps allowing other destinations or activities. Choices with respect to residential location will also have an obvious impact on mobility and transportation needs.

It is clear that the physical and architectural environments are major determinants of the impact of disability on mobility and transportation needs. For example, just as mobility within a household may be enhanced for disabled persons by hand-rails and ramps, mobility impediments outside the home, such as mountainous terrain or inclement weather, may be partly overcome by improving the quality of walking and road surfaces, decreasing the distance from the residence to the nearest bus stop and constructing gently sloping walking paths. In addition to the characteristics of the physical and social environment, mobility and transportation needs may be affected by factors such as air pollution levels and crime rates.

Regional, city and residential design also can have a large impact on mobility needs and transportation access. Most large cities and suburbs in the United States grew in an ad hoc manner, with planning for general transportation needs following growth patterns. The high-density urban core was created in the eras of the "walking-horsecar" of 1800-1890, the "electric streetcar" of 1890 1920 and the era of the "recreational automobile" of 1920-1945. Indeed, until approximately 1950 , the automobile was relegated to a secondary role in terms of America's primary mode of transportation, and the urban center effectively formed the true nucleus of the city. The "freeway era" of 1945 to the present engendered substantial changes in urban geography and culture, with a new 
decentralized landscape of economically-, socially- and racially-determined suburban zones where residents travel by car to service, commercial and employment hubs that are located on the freeways that radially and concentrically surround the former urban core. In terms of transportation, this new ordering of the American city makes the city center less accessible by private vehicle to the city's main residents (the suburbanites) than their nearby service, commercial and employment hubs. However, the public transportation systems of many cities still are ordered as if the city center were the major destination for most residents, even in suburban areas (Muller, 1986, and Bullard, 1997). The ramifications for aging residents of suburban America are dramatic. The new city landscape was designed for a highly mobile younger population, and the dearth of alternative transportation to suburban service and commercial hubs makes automobile travel an imperative for elders to maintain independence (Rosenbloom, 1989).

Knowledge of future city and regional planning activities can be important in predicting transportation needs. For example, the growing trend among states to preserve green space and limit urban sprawl may in future decades alter transportation availability and patterns (Bullard, 1997). In summary, environmental characteristics of many types are an important data need when evaluating the mobility of older women and the incumbent transportation needs. When conducting personal interview surveys on population mobility and transportation needs, these environmental attributes are not characteristics of individuals, and the data must be sought from other sources. 


\section{Population Disability/ Dysfunction and Mobility and their Relation to Gender and Socioeconomic Status.}

This section will describe the problems with assessing disability, dysfunction and mobility, as well as how it might relate to socio-economic status (SES) and gender. This is a complex area but the brief review is done with the intent of relating function to automobile driving and its cessation.

\section{A. Interpreting Disability and Dysfunction}

As noted above, the relation of disability/dysfunction and mobility is difficult to assess because there is only a small literature on mobility (as movement from one place to another) for social purposes and few surveys that contain both dimensions in detail. Thus, one important research area is the collection of data that include both physical function and disability characteristics, as well as a range of true mobility measures. However, interpreting the relation of disability to mobility is complex for several reasons:

- Disability is multidimensional and extremely complex, and there are many deficits in movements and elemental functions that would qualify. For example, these might include the ability to straighten one's knee, rotate one's wrist, grasp a small or large object and turn one's head 110 degrees in each direction. Deriving summary measures for individuals or populations that include the large number of individual characteristics available is difficult, both in representing and in interpreting them. This then creates a challenge for analyzing complex survey data. 
- Disabilities are rarely if ever isolated entities. Rather, they almost always reflect the presence of chronic medical conditions, the positive and adverse aspects of their treatments, the presence and extent of effective rehabilitation, and the long-term dysfunctional consequences of lack of movement and exercise. Acute illnesses, such as influenza, of course, cause temporary decrements in one's usual activities, but these are short term and not the subject of consideration here. Any relation of SES to disabilities may be mediated by any of these factors, or combinations thereof. For example, the greater prevalence of a disability among lower SES individuals might be due either to continuing adverse environmental exposures, greater susceptibility to the underlying disease, a poorer response to treatments and convalescence, or lesser access to effective treatment or rehabilitative services.

- The extent of disability will depend in part on the length of time in the dysfunctional state. Prolonged disuse of limbs or decreased movement or exercise for any reason might lead to an irreversible disability not subject to rehabilitation. On the other hand, some disabilities may be relatively temporary, such as when recovery occurs after a stroke, hip fracture, joint replacement surgery or a major cardiovascular procedure.

- Disability occurrence and severity will also depend on the types of illnesses initiating and maintaining the disability. Unfortunately, multiple conditions and disabilities occurring in the same older individual is the rule with increasing age, and, again, summarizing, indexing and interpreting these conditions vis $a^{\prime}$ vis auto driving can be difficult. The differences in disease distributions causing physical 
disability can be critical in explaining age- and gender-related mobility problems. For example, if a woman has difficulty in climbing a flight of stairs, the concomitant ability to operate a motor vehicle may be very different when the underlying disease is heart failure than when it is osteo- (degenerative) arthritis of the knee. In the latter case, altering vehicle control systems might provide a solution; in the former situation it would not be of value.

- Multiple conditions (also called co-morbidity) or conditions affecting multiple functions make it difficult to evaluate the impact of a single disability on motor vehicle operation. For example, in evaluating the relation of hearing loss to crash risk among elders (Gresset and Meyer, 1994), the role of hearing loss may depend on its causes. If it is due in part to stroke or antibiotic treatment of chronic infections due to cancer or AIDS, then the implications for crash risk may be different than if it is due to age-related neuro-sensory deficits. An important implication for further research is that population sample sizes should be large enough so that research on various causes of disability can be evaluated individually and in appropriate combinations. Additionally, the causes of various disabilities should be determined in order to interpret the research and to develop appropriate policy.

- The relation of disability status to mobility, based on the above discussion, will in great measure depend on the mediating effects of the scope and severity of the disabilities and the underlying medical conditions. For example, some serious medical conditions may mandate more transportation for medical services, but deter other motivations for mobility. 
- Among older people, general disabilities may be thought of as due to physical ailments, but in fact it is likely that disabilities in complex tasks and activities such as using the telephone, balancing a checkbook or operating a motor vehicle may in fact be due more to cognitive deficits or cognitive impairment, whether or not overt clinical dementia is present (Manton, Stallard and Corder, 1998; Gauthier, Gélinas and Gauthier, 1997). The prevalence of clinical dementia sufficient to cause functional disabilities is about $2 \%$ among persons 65 years of age, but may be as high as $20-40 \%$ among those 85 years and older (Doble et al., 1997; Gauthier, Gélinas and Gauthier, 1997). In the past, cognitive impairment had received less attention because of inadequate understanding of dementing processes and inadequate tools to assess cognitive capacity. In addition, the cognitive sciences and the understanding of cognitive function have grown rapidly in the past decade. As interest and capacity have grown with the increasing number and age of America's elders, it is clear that what might have been characterized as a physical disability actually may be largely or wholly of cognitive origin. This has great implications for using all types of transportation, including motor vehicles, and requires considerable attention when assessing gender differences in disability, mobility or transportation use. The methods and prospects for preventing cognitive disability and its consequences may often be very different than those for physical disability, and mechanisms for maintaining mobility and preserving function and transportation use may be quite different from a policy perspective. 


\section{The Relation of Population Disability, Mobility, and Transportation Status and}

\section{Quality of Life}

In this section, we will review the major trends in disability, mobility, transportation and quality of life among older populations, with an emphasis on gender differences. As the discussion progresses, deficits in our understanding and data needs will be highlighted.

\section{A. Disability and Gender}

Gender differences in older persons' mortality rates have been welldefined in the United States: men have consistent and persistently higher mortality rates than women and have a life expectancy from birth of approximately six years less than women (Centers for Disease Control and Prevention, 1997). That older women report both greater morbidity and more utilization of health services then older men (Verbrugge, 1983) while having better survivorship is a paradox not fully explained. The reasons for this paradox are likely complex, and include fundamental biological and physiological differences between men and women as well as psychological and sociological differences in the perception of illness and the threshold for reporting symptoms and disability in both the survey and clinical settings. The female-male differences in physical disability seen in population surveys is not likely to be due to gender variation in self-reported function, since the differences have been confirmed by physical performance testing (Merrill et al., 1997). There is a clear need for more surveys using performance testing to further explore the causes and consequences of gender differences in disability. Surveys that explore these 
differences also need to exploit performance testing that is directly relevant to transportation and mobility issues.

Some investigators have suggested that the disability-mortality paradox between men and women may be at least in part due to substantial differences in the underlying causes of the disability. For example, women more likely may have disability attributed to chronic, non-fatal illnesses such as migraine headaches and arthritis than men, while disability due to heart disease may be more common in men (Verbrugge, 1985, and Kandrack and Grant, 1991). This in turn has important implications for forecasting disability rates for the next several decades. For example, if relatively more disability among men is due to coronary heart disease (CHD), they may experience improvements in age-specific disability rates in the next decade because $\mathrm{CHD}$ rates have been declining since the mid1960 's. On the other hand, there is little evidence that degenerative arthritis rates, more prominent in women, have been declining. Thus, forecasting future disability rates among older women requires predicting trends in the underlying disabling illnesses, a most difficult task.

In analysis of data from the New Haven Established Populations for the Epidemiologic Study of the Elderly (EPESE) (Cornon-Huntley, et al., 1993), women over age 70 years reported themselves as 1.8 times more likely than men to be disabled in terms of seven activities of daily living (ADL), 1.9 times more likely than men to have a gross mobility (walking) limitation, and 2.6 times more likely than men to have a limitation in the ability to move their joints (range-ofmotion). These results are based on self-report, and could be due to the 
possibility that women over-report and/or men under-report their disablements.

However, as noted above, differences in the reporting of disability in general accurately reflect gender differences in disability (Merrill et al., 1997), and other research suggests similar findings in terms of gender and disability (Penning and Strain, 1994; Rogers, Rogers and Belanger, 1992). 
Table 1: Women reporting difficulty in performing basic activities of daily life (ADLs) and indicators of activities of daily life (IADLs)*

\begin{tabular}{|c|c|c|c|c|c|}
\hline & $\begin{array}{c}\text { EPESE - } \\
\text { East Boston } \\
\quad n=2357\end{array}$ & $\begin{array}{c}\text { EPESE - Iowa } \\
\text { and Washington } \\
\text { Counties } \\
\mathrm{n}=2255 \\
\end{array}$ & $\begin{array}{c}\text { EPESE - } \\
\text { New Haven } \\
\text { n=9768 }\end{array}$ & $\begin{array}{c}\underset{\mathbf{L O A}}{\mathbf{\mathbf { T } ^ { 2 }}} \\
\mathrm{n}=4651 \\
\end{array}$ & $\begin{array}{c}1994 \\
\text { NLTCS }^{3} \\
n=19171 \\
\end{array}$ \\
\hline \multicolumn{6}{|l|}{ Walking $\dagger$} \\
\hline 65.69 & 20.5 & 9.3 & 16.4 & - & 6.8 \\
\hline $70-74$ & 24.5 & 14.3 & 17.8 & 28.3 & 7.3 \\
\hline $75-79$ & 37.4 & 22.5 & 32.6 & 33.7 & 9.7 \\
\hline $80-84$ & 57.3 & 39.3 & 32.3 & 48.7 & 15.8 \\
\hline $85+$ & 70.7 & 58.9 & 61.2 & 61.0 & 35.5 \\
\hline \multicolumn{6}{|l|}{ Eating } \\
\hline $65-69$ & 1.2 & .4 & 1.9 & - & .7 \\
\hline 70.74 & 1.6 & .3 & 1.4 & 1.0 & .7 \\
\hline $75-79$ & 2.4 & 1.2 & 2.2 & 1.8 & .9 \\
\hline $80-84$ & 5.0 & 2.2 & 1.1 & 2.9 & 1.5 \\
\hline $85+$ & 12.5 & 4.1 & 4.7 & 4.2 & 5.3 \\
\hline \multicolumn{6}{|l|}{ Dressing self } \\
\hline $65-69$ & 5.1 & 1.3 & 3.7 & - & 3.5 \\
\hline 70.74 & 7.5 & 1.4 & 3.1 & 5.0 & 3.7 \\
\hline $75-79$ & 8.7 & 2.2 & 5.0 & 6.1 & 3.4 \\
\hline $80-84$ & 17.2 & 6.4 & 5.3 & 9.7 & 4.7 \\
\hline $85+$ & 22.3 & 7.9 & 14.9 & 17.9 & 12.0 \\
\hline \multicolumn{6}{|l|}{ Bathing } \\
\hline $65-69$ & 4.5 & 2.9 & 6.6 & - & 3.3 \\
\hline $70-74$ & 8.4 & 2.2 & 4.2 & 9.1 & 3.8 \\
\hline $75-79$ & 15.8 & 4.1 & 8.6 & 11.0 & 4.4 \\
\hline $80-84$ & 28.2 & 9.7 & 14.2 & 18.8 & 7.3 \\
\hline $85+$ & 43.5 & 12.9 & 29.4 & 30.2 & 20.0 \\
\hline \multicolumn{6}{|l|}{ Grasping object } \\
\hline $65-69$ & 13.9 & 12.3 & 7.4 & - & 一 \\
\hline $70-74$ & 17.5 & 13.5 & 7.3 & 10.3 & - \\
\hline 75.79 & 21.2 & 19.2 & 14.4 & 12.3 & - \\
\hline $80-84$ & 31.4 & 27.3 & 11.9 & 16.3 & - \\
\hline $85+$ & 43.1 & 36.9 & 20.2 & 16.7 & - \\
\hline \multicolumn{6}{|l|}{ Stooping } \\
\hline $65-69$ & 49.8 & 42.0 & 41.9 & - & - \\
\hline $70-74$ & 59.5 & 47.4 & 43.9 & 41.9 & - \\
\hline $75-79$ & 60.0 & 54.5 & 59.1 & 43.8 & - \\
\hline $80-84$ & 73.6 & 68.3 & 52.5 & 54.1 & - \\
\hline $85 \div$ & 79.2 & 75.4 & 58.0 & 58.1 & - \\
\hline \multicolumn{6}{|l|}{$\begin{array}{l}\text { Lifting/moving } \\
\text { objects } \neq\end{array}$} \\
\hline $65-69$ & 54.9 & 31.3 & 38.3 & - & - \\
\hline $70-74$ & 59.9 & 40.2 & 36.0 & 41.3 & - \\
\hline $75-79$ & 61.0 & 51.5 & 46.2 & 49.3 & - \\
\hline $80-84$ & 74.4 & 61.5 & 43.7 & 61.0 & - \\
\hline $85+$ & 73.8 & 69.2 & 48.1 & 70.3 & - \\
\hline \multicolumn{6}{|l|}{$\begin{array}{l}\text { Transferring self } \\
\text { from bed }\end{array}$} \\
\hline $65-69$ & 2.9 & 3.0 & 2.6 & - & 2.6 \\
\hline $70-74$ & 4.5 & 2.9 & 2.4 & 8.7 & 2.5 \\
\hline 75.79 & 7.3 & 4.9 & 6.2 & 9.2 & 2.7 \\
\hline $80-84$ & 13.7 & 9.2 & 8.0 & 14.2 & 2.8 \\
\hline $85+$ & 22.8 & 10.3 & 15.0 & 22.3 & 10.2 \\
\hline \multicolumn{6}{|l|}{$\begin{array}{l}\text { Reaching arm over } \\
\text { head }\end{array}$} \\
\hline 65.69 & 22.2 & 15.2 & 13.3 & - & - \\
\hline $70-74$ & 29.0 & 19.2 & 11.4 & 17.2 & - \\
\hline $75-79$ & 31.5 & 23.9 & 25.8 & 18.1 & - \\
\hline $80-84$ & 42.1 & 31.1 & 16.4 & 24.5 & - \\
\hline $85+$ & 44.4 & 34.9 & 24.9 & 30.1 & - \\
\hline
\end{tabular}


* women reporting in survey "some inability" to do function to "complete inability" to do function

1 data from Established Populations for Epidemiologic Studies of the Elderly: Resource Data Book. U.S. Dept. of Health and Human Services, Public Health Service, National Institutes of Health. Bethesda, Md.,1986.

${ }^{2}$ data from The Longitudinal Study of Aging, 1984-90 computer file. SETS version 1.21. U.S. Dept. of Health and Human Services, Public Health Service, Centers for Disease Control and Prevention, National Center for Health Statistics. Hyattsville, Md., 1993.

${ }^{3}$ data from National Long-Term Care Survey, NLTCS Public Use Data, 1982, 1984, 1989, 1994. Duke University Center for Demographic Studies. Durham, NC, 1998. NLTCS data is from screening portion of interview and therefore does not cover as many ADLs and IADLs as the EPESE and LSOA studies.

$\dagger$ for EPESE surveys, walking is determined by one-half mile distance; for LSOA II, walking is determined by onequarter mile distance; for NLTCS 1994, walking is determined by "going outside"

$\ddagger$ for EPESE surveys, object movement is determined by a general query with moving furniture used as an example; for LSOA II, lifting is determined by holding a 25 pound object 
Table 1 is a compilation and summary of the prevalence rates for various commonly assessed physical function status measures in population studies, showing only data for women 65 years of age and older. Despite the fact that they were performed as much as 12 years apart and are both national and local in scope (although all are geographically-referent), there is general consistency in the findings. Overall, physical dysfunction and disability measures increase with age. Disablement is less common for the upper extremities than lower extremities, suggesting that difficulty in using forms of transportation that require walking (such as using urban buses) will come earlier in life than difficulties in operating an automobile, which requires more manipulation with the hands and arms. The table also shows that, overall, the prevalence of disability is substantial; this has important implications for transportation policy. Finally, while only a few surveys are sampled here, we found that many comprehensive geriatric surveys in the United States (summarized in detail in the appendix) uniformly do not use measures of disability that can be related directly to the specific functions of using various transportation modes.

An important issue is whether the long-term trend in disability rates is changing among older women in the United States. This issue has been argued in past decades, and remains controversial. More recently, evidence from one survey (The National Long Term Care Survey) was interpreted to show that over a decade there has been a small decrease in the prevalence of disability (Manton, Corder and Stallard, 1997; Manton, Stallard and Corder, 1998). However, this has not been well-evaluated in other surveys and is subject to several assumptions 
in data collection and self-report of disablement. A decline in age-specific disability might in fact be expected with increasing survivorship and no evidence that age-specific institutionalization rates are increasing. Also, the reports basically address physical disability, and do not deal with the issue of whether there has been a long-term change in cognitive capacity of populations, which is critical to using transportation. Our view is that this reported secular trend, while desirable, is not proven and requires further verification. If disability rates are declining, this should lead to some increase in the ability to maintain automobile operation and other transportation use for a longer period of time.

An ancillary but critical question is the trajectory of social and transportation activity among those who are disabled. There is much less population data available on this issue, particularly for older persons. A recent publication from the National Institute on Disability and Rehabilitation Research suggested that disabled persons 16-64 years of age are not enjoying any increase in social activity or employment earnings relative to those not disabled (Kaye, 1998). If this is also true for older persons, it suggests that the consequences of disability for mobility will continue into future years unless important changes in transportation access occur. Little is known about mobility among those with early- or mid-life-onset disability, no matter whether such disability is designated by self-report, clinical diagnosis or administrative action; this is another area in need of characterization on a population basis. 


\section{B. Mobility and Quality of Life}

Although research has focused on the relationship between physical mobility (often measured by ambulation status) and measures of health-related quality of life (HRQOL) and health-related functioning, little data has been collected on the direct relationship between community-related mobility (in terms of driving and other transportation) and HRQOL or other health-related functional measures; this is clearly an important data need with respect to older women and transportation. Research on the relation between social functioning (self-rated and formally scored) as a proxy for within-community mobility and functional status measures (including cognitive and other comorbidity) shows that decreased functional status is highly associated with lower social functioning, further suggesting that decreased mobility is also associated with poorer health and substantial morbidity (Verbrugge, Reoma and Gruber-Baldini, 1994).

Research also suggests that elders view community-related mobility as most vital to their maintenance of social, family and community relationships, with a higher priority than mobility as a requisite for utilization of health services (Coughlin and Straight, 1998). Indeed, driving one's own vehicle was found to be associated with higher levels of life satisfaction, higher adjustment, less loneliness and better perceived control. In addition, as control over the transportation mode is increased (from scheduled public transportation to on-call private modes, acquiring rides from acquaintances and family and driving one's own automobile), measures of life satisfaction increase (Gonda, 1982). A study from the AAA Foundation for Road Safety Research reported that $81.8 \%$ of current and 
$75 \%$ of former elder drivers felt that driving was "vitally important" to their wellbeing (Rabbitt, Carmichael, Jones and Holland, 1996).

The social impact of loss of mobility is clearly important, and in a certain sense the phenomenon of "co-piloting" in automobile operation may be an example of a social function that itself enhances mobility. Older adults develop a broad array of coping strategies to assist one another with the losses of old age (Atchley, 1994). Although we are unaware of a population-based, systematic study of the phenomenon, non-driving spouses, usually women with better directional awareness or sharper vision, are known to assist their driving partner, who may have a physical or cognitive disability that disrupts driving (Burkhardt, Berger and McGavock, 1998). This, too, requires further study, as an aid to mobility and social activity of its own.

The high percentage of elder men who continue to keep an automobile, maintain a license and drive in the community has lead several authors to speculate about a strong connection between elder men's self-image and driving; whether an increasingly automobile-reliant and independent female baby-boom cohort will follow this pattern remains to be seen, and should also be the subject of further population-based research.

Quality of life perception varies between men and women both when disability occurs and when assistance is received for that disability. While reported quality of life and general well-being levels are significantly lower for both men and women who report physical disability, in one study men reported lower levels of perceived well-being associated with the receipt of assistance from 
individuals or devices. This was not found in women, and the authors concluded that women are more receptive to assistance for their disability (Penning and Strain, 1994).

\section{Economic Status and Mobility/Automobile Operation}

America's elders have a great distribution of economic means. We are in a period where pension income is at its highest level ever. On the other hand, persons over 65 years are the second most impoverished demographic sector, after children. In part because of the difficulty of measuring economic means, information on the relation between economic means and automobile ownership and operation is difficult to assess. General driving rates are noted below, and this section briefly summarizes the demographic correlates of automobile driving among older American women. The association of general disablement with socio-demographic variables is also briefly noted.

Disablement, income and education. Research has consistently revealed a strong relationship between disablement (or physical mobility) in elders and levels of income and educational attainment. The precise nature of this relationship, however, is somewhat complex and "confounded" by the multitude of factors which income and education represent, such as health behaviors, health care utilization, employment and other environmental factors.

The correlation between higher education and life without disability are striking. An analysis of the Longitudinal Study of Aging 1984, a national sample, revealed that persons over age 70 years with over seven years of education were over twice as likely to remain free of disability after two years than those with six 
years or less of education (Harris, et al., 1989). Further analysis of the same data suggested that family income over $\$ 25,000$ was associated with a similar halving of risk of incident disability after two years of follow-up (Mor, et al., 1989).

Similar studies, including the Established Populations for Epidemiologic Studies of the Elderly (Guralnik, et al., 1993), the Framingham Disability Study (Pinsky, Leaverton and Stokes, 1987) and the Alameda County, California, Study (Guralnik and Kaplan, 1989), yielded similar conclusions on the "protective" relationship of higher income and education on disability-free life.

Interpreting the associations among indicators such as educational attainment and income, particularly among elders, is understandably complex, as noted above. The associations may be predominately economic in nature, with those having higher income and education also possessing better access to health care and a safer physical and social environment. The associations may also be socio-behavioral in nature, as those with better education may have been better informed and may have practiced more health-giving hygienic behaviors, with a more informed understanding of self-diagnosis and clinical preventive techniques and services. Other possible intermediaries between physical functioning and education or income include former and current employment (those with lower education filling more dangerous or taxing jobs) or differences in physicians' treatment patterns of different social classes (Pinsky, et al., 1987).

In order to pursue these associations, we analyzed data for women 70 years and older from the baseline survey of the Assets and Health Dynamics Study of Older Americans. We constructed a regression model in which the 
dependent variable is current automobile driving status, and the independent variables are three simple function status variables: ability to do heavy housework, walking up and down stairs without difficulty and ability to walk onehalf mile. The results are as follows:

One

Two

Three

In summary, the model shows that, in cross-sectional context, simple measures of function were highly related to quitting driving. However, when other factors are explored in addition to physical function, such as age, annual income, net economic worth and living alone, all of these were significant and independent predictors of driving status, even after adjusting for the effect of physical function. At least preliminarily, these data suggest that personal and family economic factors may have an independent role in the use of transportation, something that needs further study. Population data on income and driving status are shown below. What is missing here is the pathway by which women drivers had quit, including the role of families, insurance companies, health professionals and the state. 


\section{Automobile Driving Rates Among Older American Women}

According to results from the 1995 Nationwide Personal Transportation Survey (NPTS), 82 percent of women over age 65 years report themselves as active automobile drivers; until age 80 years the majority of women report themselves as drivers. In this cross-sectional survey, it is about at age 75 years when older women's driving rates begin to decline substantially. At age 85 years only 36 percent report themselves as currently driving (Figure 1).

Figure 1. Current female drivers, from 1995 NPTS

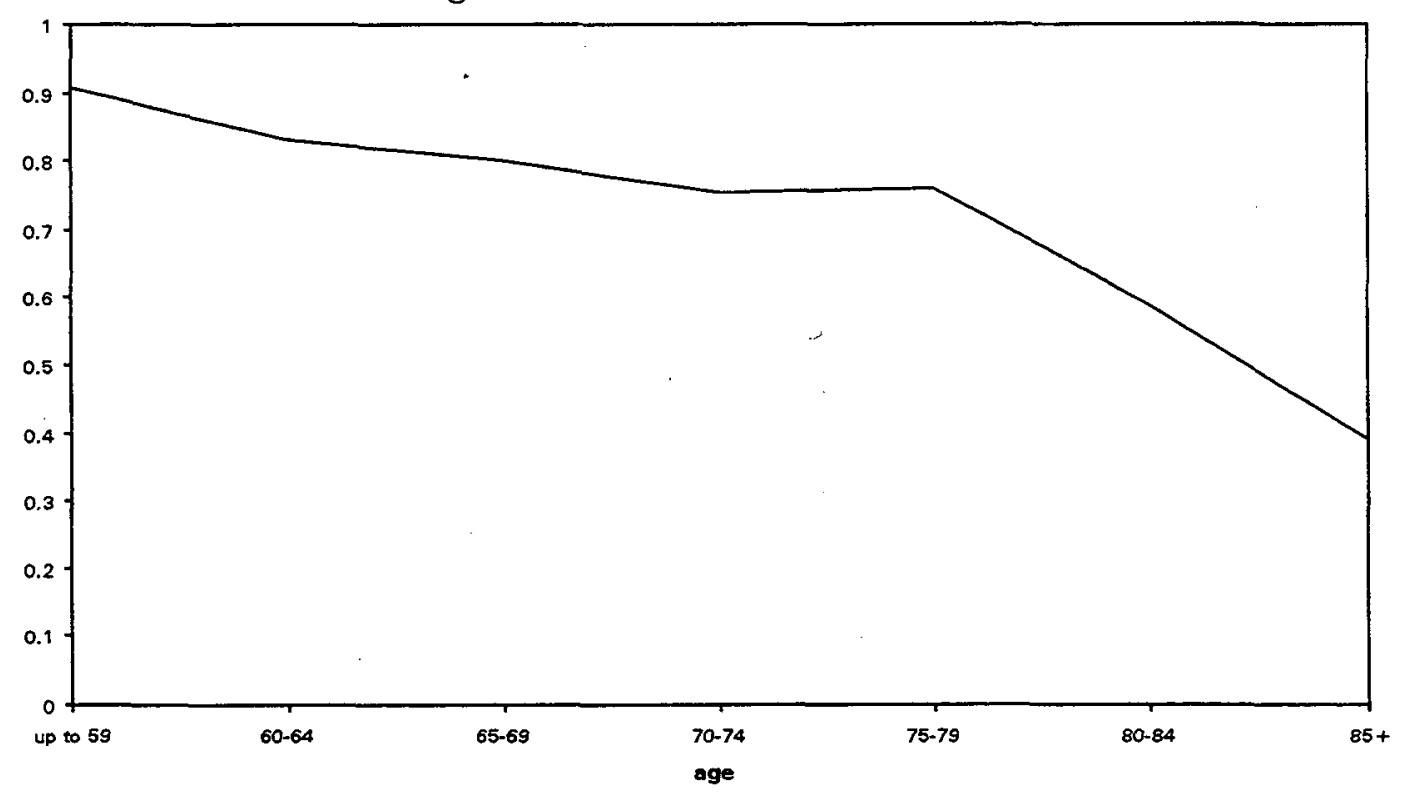

From 1995 Nation's Travel: Early Results from the 1995 Nationwide Personal Travel Survey, US Department of Transportation Bureau of Transportation Statistics and the 1995 Nationwide Personal Travel Survey

In contrast, 95 percent of men in the 1995 NPTS report current driving at ages 60 64 years and 78 percent of men over age 85 report themselves as drivers. The difference in self-reported driving status between men and women has narrowed over the past decade. The 1983 NPTS indicated that 75 percent of women age $60-64$ were licensed to drive, and that number increased to 82 percent by 1990. (By comparison, the number of 
men licensed to drive increased from 93 to 95 percent.) Of those age 85 years and above, the percent of those licensed to drive increased from 11 to 24 percent (Burkhardt, Berger and McGavock, 1996). As noted above, we expect that with each succeeding generation of elders, the proportion of older women drivers is likely to approach and equal that of men.

Important ramifications exist for elder women transportation issues as the current cohort of "baby boom" women age. By all measures of current and predicted mobility, including licensing, current mileage driven and vehicle ownership and access, baby boom generation women (currently aged 40-55 years) have substantially higher levels than today's women 65 years and older when they were the same age. As shown in Figure 5, when the current baby boom women are over age 65 years, they will more likely be the head of a household, more well educated and more likely to have had a long career in the labor force. This suggests that in the next decades demands for increased mobility among older women will be greater for social activities, including employment, recreation, community volunteering and support for other family members (Jette, 1997). This in turn will have important implications for road construction and the environmental burdens of the automobile.

As noted above, automobile driving status in older women is associated with personal and family income, as shown in Figure 2 from the NPTS. The situation for older women living alone is different than those in a multiple-person household, with significantly more elder women who live alone continuing to drive, at least past the age of 75 years (Figure 3). This can be interpreted as a selection factor, with less healthy older women driving less and being less capable of living alone. However, it is also 
worth exploring whether the continued ability and willingness to drive is associated with a longer period of independent living. Figure 4 , which shows the relation of age and income to driving status only among women living alone suggests that there is more income discrimination as to driving status than among older women in general. This too would seem to merit further investigation as to the determinants of this situation and the possibility that living alone might be a risk factor for mobility interventions.

Figure 2. Proportion of women who curently drive as a function of age and household income

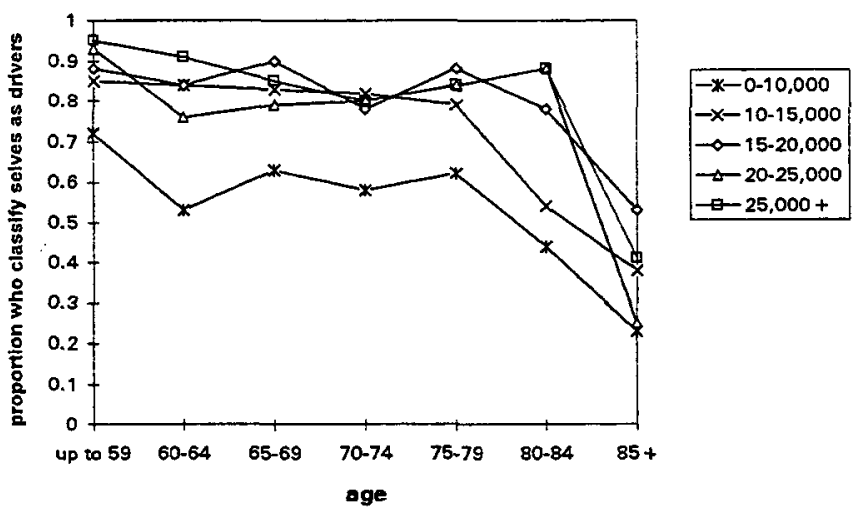

From 1995 Nation's Travel: Early Results from the 1995 Nationwide Personal Travel Survey, US Department of Transportation Bureau of Transportation Statistics and the 1995 Nationwide Personal Travel Survey 
Figure 3. Proportion of current female drivers as a function of age and household size
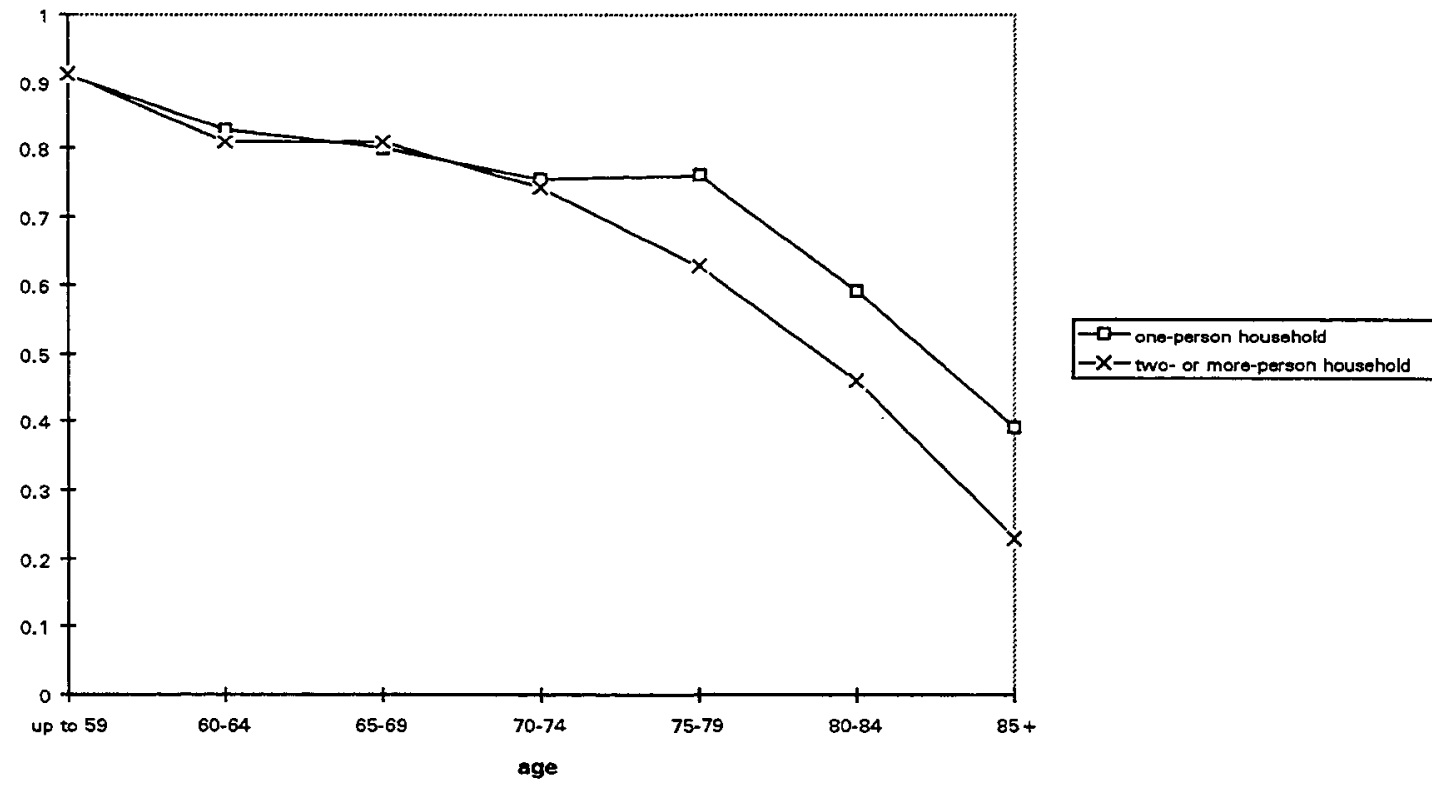

From 1995 Nation's Travel: Early Results from the 1995 Nationwide Personal Travel Survey, US Department of Transportation Bureau of Transportation Statistics and the 1995 Nationwide Personal Travel Survey

Figure 4. Proportion of current female drivers who live in a single-person household as a function of age and household income

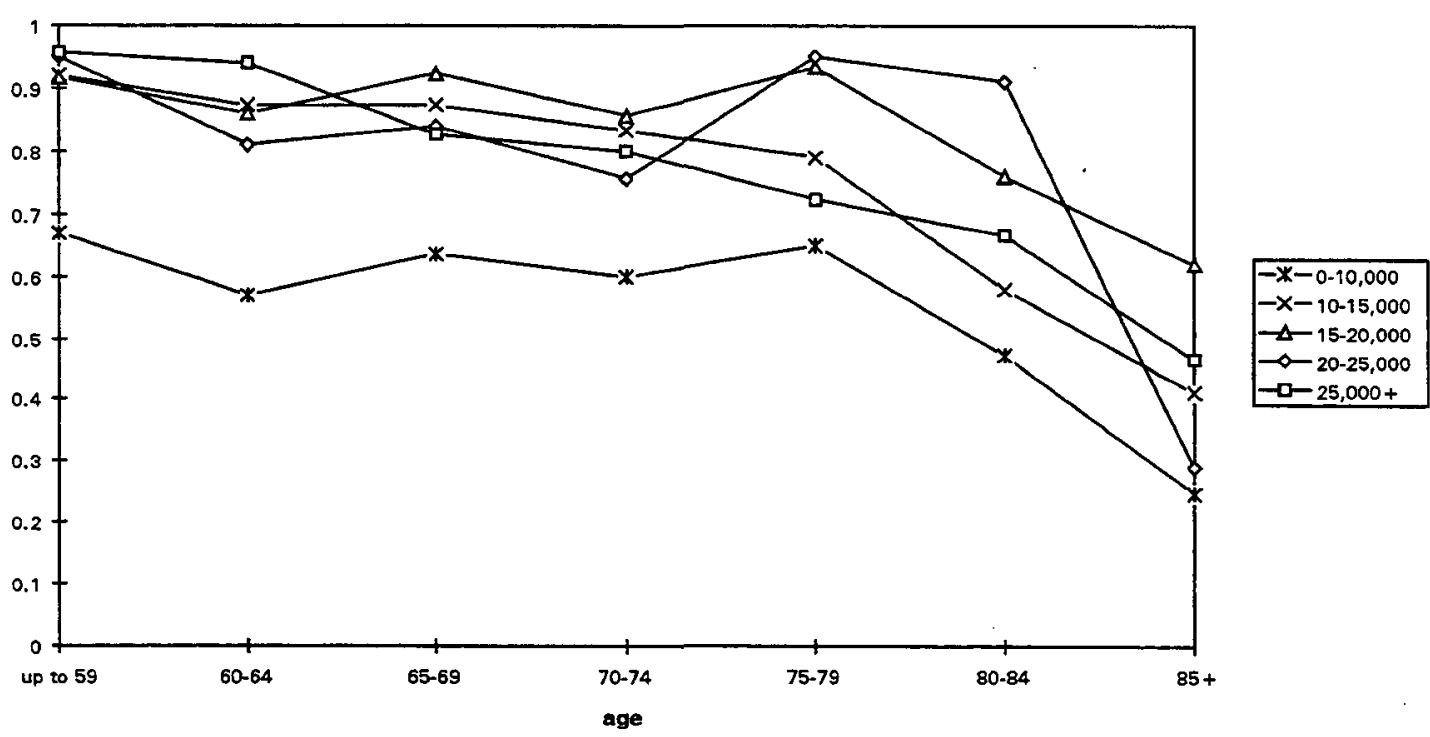

From 1995 Nation's Travel: Early Results from the 1995 Nationwide Personal Travel Survey, US Department of Transportation Bureau of Transportation Statistics and the 1995

Nationwide Personal Travel Survey 
Figure 5. Indicators of women's independece

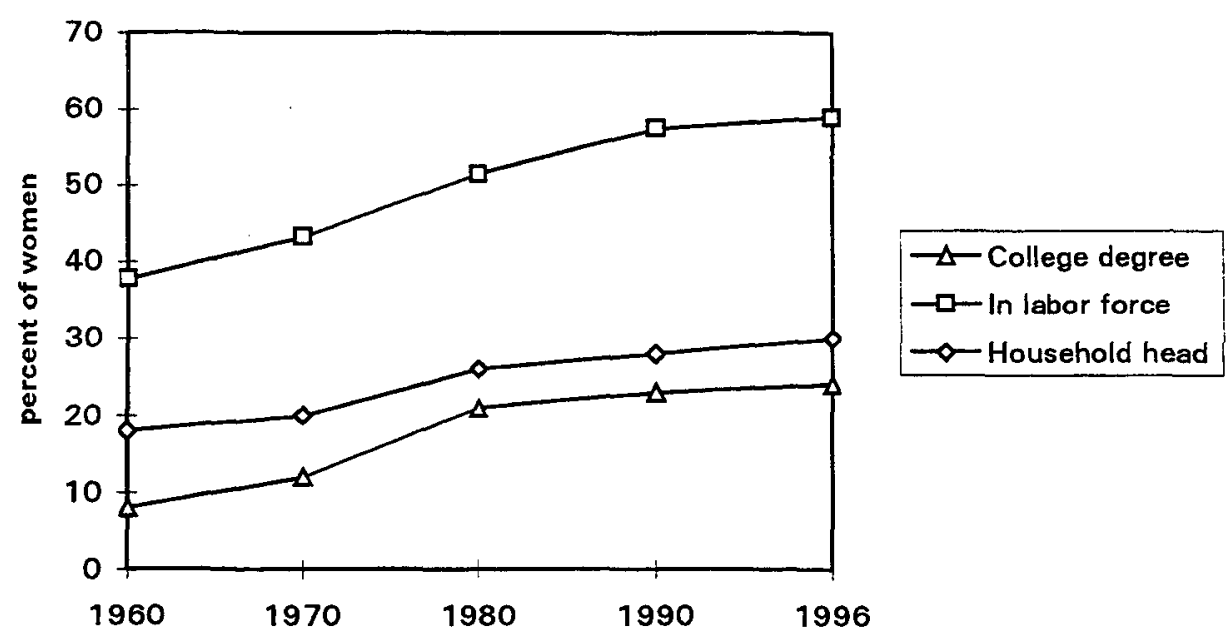

SOURCE: Bianchi and Spain 1996; U.S. Bureau of the Census 1996, 1997

\section{Alternative Transportation for Older Women}

As older women choose to give up driving based on varying degrees of physical and cognitive disability from aging and health problems, the need increases for alternative transportation to replace automobiles, at least for provision of intracommunity mobility. However, public transit, paratransit and taxis or other private transportation do not fully provide the mobility older women expected with the automobile, and therefore many elders do not choose to pursue public transportation as a viable alternative to automobile travel. The 1990 Nationwide Personal Transportation Survey indicated that elders' reliance on automobile travel is currently increasing, with $91 \%$ percent of elders' trips in 1990 by private vehicle (compared with $86.7 \%$ in 1983 ) and $1.0 \%$ of elders' trips in 1990 by public transit (compared with $2.7 \%$ in 1983) (Table 
2). An important change is the drop in proportion of persons walking as a transportation mode. :

Table 2. Percentage of Person-Trips by Mode, 1983 and 1990

\begin{tabular}{llll|lll}
\hline & \multicolumn{3}{c}{1983} \\
\cline { 2 - 7 } Mode & $\mathbf{6 5 - 7 4}$ & $\mathbf{7 5 - 8 4}$ & $\mathbf{8 5 +}$ & $\mathbf{6 5 - 7 4}$ & $\mathbf{7 5 - 8 4}$ & $\mathbf{8 5 +}$ \\
\hline Private Vehicle & 86.7 & 83.0 & $\mathbf{7 8 . 7}$ & 91.0 & 88.0 & 81.0 \\
Public Transit & 2.7 & 1.7 & 4.0 & 1.0 & 1.8 & 3.2 \\
Walk & 9.8 & 12.0 & 13.0 & 6.0 & 8.0 & 10.5 \\
\hline \multicolumn{3}{c}{ 1990 Nationwide Personal Transportation Study; Early Results. } \\
\end{tabular}

The inability of alternative transportation to provide the mobility of the automobile is in part a function of an increasingly suburban American elder population. While the high density of the urban core may support a transit system that can offer bus routes that serve most of the city within two blocks of a bus stop, a less dense suburbia is much less suited to traditional public transportation. Moreover, even if public transportation were offered within two blocks of each origin and destination (an "ideal" public transit situation) that an elder may need to reach, transportation time is significantly greater for public transportation than automobile travel (Table 3). Even assuming an ideal situation, the National Research Council estimates that between $30 \%$

Table 3. Time Consumed by Alternative Modes for Average One Way Trip Now Taken by Vehicle for People Over Age 65

\begin{tabular}{lcccc}
\hline Trip Purpose & $\begin{array}{l}\text { Average Vehicle } \\
\text { Trip Length }\end{array}$ & Driving & $\begin{array}{l}\text { Walking } \\
\text { (time in } \\
\text { minutes) }\end{array}$ & $\begin{array}{l}\text { Ideal Public } \\
\text { Transit }\end{array}$ \\
\hline Work & 5.8 & 10 & 116 & 33 \\
Work-related & 9.2 & 16 & 184 & 47 \\
Shopping & 4.4 & 8 & 88 & 28 \\
Family/Personal & 4.3 & 7 & 86 & 27
\end{tabular}




\begin{tabular}{lllll} 
Doctor/dentist & 7.9 & 14 & 158 & 42 \\
School/church & 4.5 & 8 & 90 & 28 \\
Vacation & 28.1 & 48 & 562 & 122 \\
Visit Friends & 9.1 & 16 & 182 & 46 \\
Social/recreation & 8.3 & 14 & 166 & 43 \\
\hline
\end{tabular}

and $60 \%$ of suburban elderly persons could not make one-way trips under 30 minutes (Rosenbloom, 1993). Two blocks of foot travel may also be an unreasonable health burden for many less ambulatory elders. The public and alternative transportation availability situation is even more acute for rural older woman, with service quite limited and offered in few areas of the United States.

Though paratransit programs are available in many communities, use is quite limited, estimated at less than $18 \%$ of the eligible population (Rosenbloom, 1993). Reasons for this low use are many:

- Many programs place heavy restrictions on paratransit eligibility, limiting use to those with severe handicaps and not to those who are simply too disabled to walk the few blocks (especially in inclement weather) to use regular public transportation.

- Though many programs offer curb-to-curb service, assistance to the door may not be available, and scheduling procedures may limit use by the cognitively impaired.

- Service may not be available on weekends, and may not extend eligibility to accommodate those who are unable to drive in poor weather or after dark.

The reason for these barriers to widespread use include the prohibitively high cost of this specialized service, estimated at approximately ten dollars per one-way trip per 
individual, and the continually changing physical and cognitive status of disabled elders which do not lend themselves well to the rigid requirements of paratransit.

Private transportation including taxi services, while also costly, is an attractive option in an era of public to private sector outsourcing. Although arrangements including public subsidies for taxi services or negotiated taxi rate cuts for a guaranteed number of elders may provide a plausible alternative in some areas, public utilization of private transportation is not standard (Rosenbloom, 1989). It has also been reported that some elders with sufficient fiscal means do not use taxis because of fear of crime and because of such use being a visible indicator of "being rich," that is, flaunting a degree of wealth that peers do not possess.

As noted, a special problem in transportation availability is the difference in rural vs. urban access. As anticipated, rural elder women are in general less able than urban women to rely on public transportation for intra-community mobility (Figure 6). For this reason as well as social reasons, rural elder women are more likely to currently drive (Figure 7). 
Figure 6. Proportion of elder women in urban and non- urban zip codes who feel adequate access to public transportation

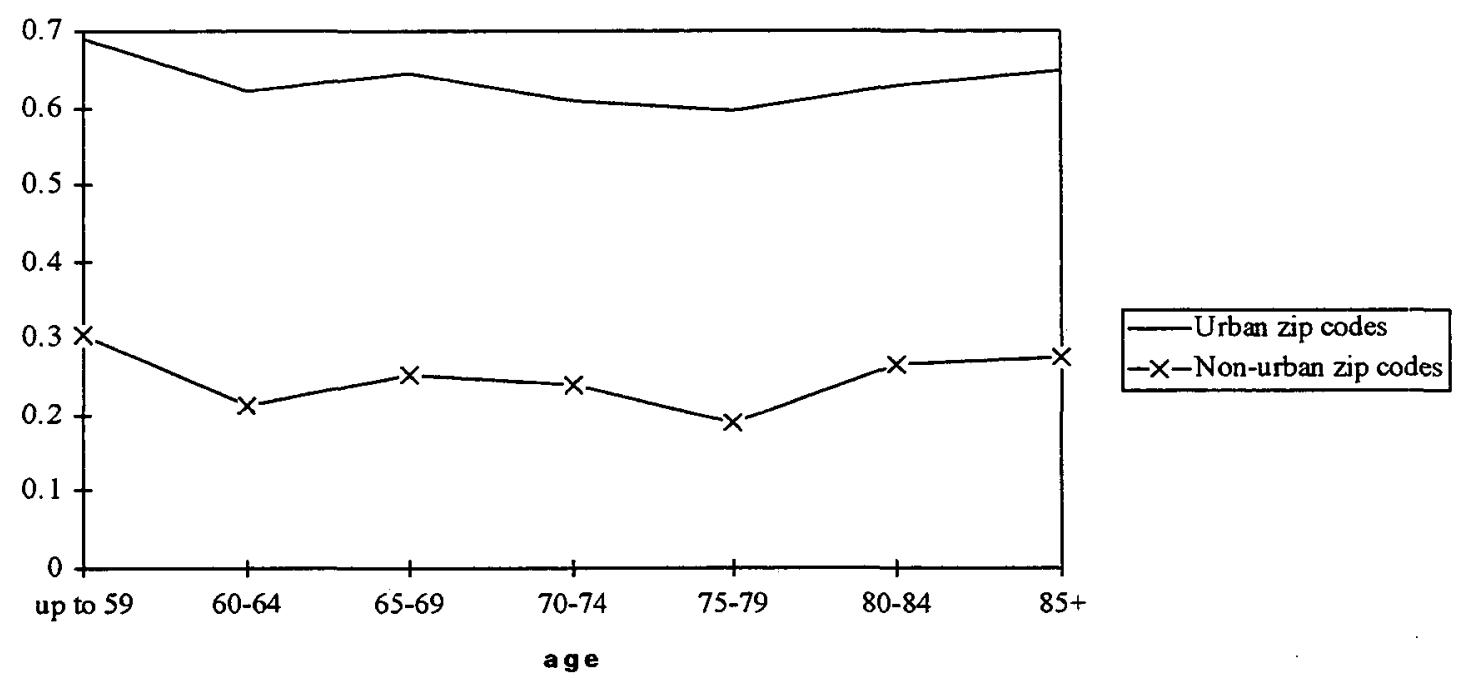

From 1995 Nation's Travel: Early Results from the 1995 Nationwide Personal Travel Survey, US Department of Transportation Bureau of Transportation Statistics and the 1995 Nationwide Personal Travel Survey

Figure 7. Proportion of elder women who currently drive in urban and ruralcensus block codes

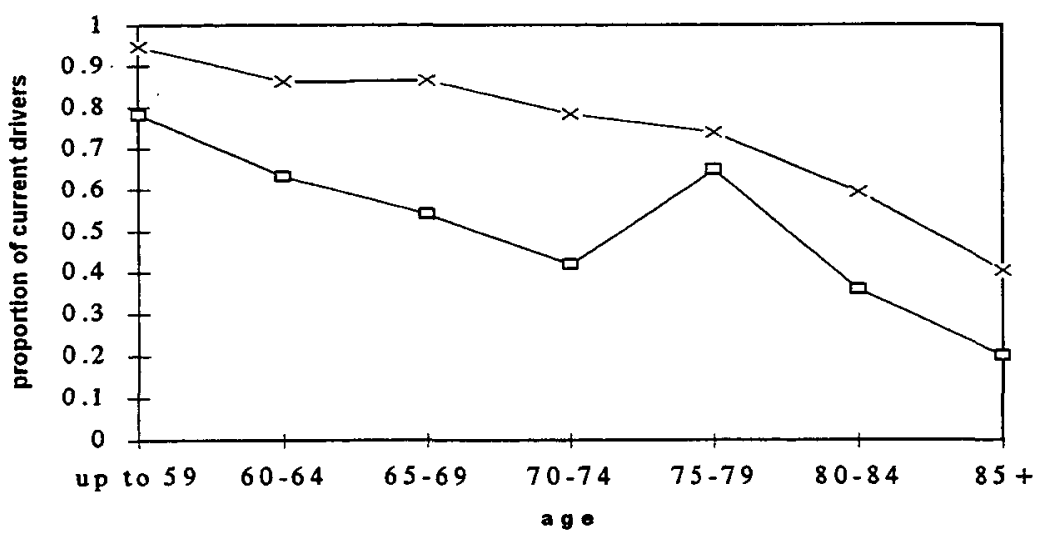

From 1995 Nation's Travel: Early Results from the 1995 Nationwide Personal Travel Survey, US Department of Transportation Bureau of Transportation Statistics and the 1995 Nationwide Personal Travel Survey 
This may be in part due to a selection bias in which healthier elder women continue to live in rural areas whereas their more physically disabled peers move into town. Investigation is needed to determine if rural women continue to drive despite disablement more than their urban peers due to the lack of mobility options in rural areas. Analysis of the Established Populations for Epidemiologic Studies of the Elderly suggest that few older women feel that public transportation in rural areas meets their transportation needs, more specifically that rural public transportation does not offer service to areas that are desired destinations (Foley, Eberhard, Ostfeld, Wallace and deWolf, 1990). Walking, usually the chief alternative mode of transport to the car, is simply not a viable alternative in many rural settings. Thus, without alternatives to driving, rural non-driving elders face even higher levels of social isolation than their counterparts in the city (Gonda, 1982). 


\section{Conclusions Concerning Older Women's Safe Mobility and Transportation}

Needs

This section will synthesize the information contained in the above report, and make recommendations for improved data collection on the central issues at hand. While there are substantial gaps in available data (with suggestions made below) some tentative conclusions can be drawn:

1. The number of older women (and men) is increasing rapidly in the United States due to general population growth, immigration and surviving longer. This in itself is an imperative for enhanced planning efforts for the expected increase in mobility and transportation needs.

2. Several trends in the health, economic and social status of older women will make these planning efforts complex. Tomorrow's older women will likely have somewhat improved longevity and possibly somewhat less disability for a given age than today's. They will more likely have had a long labor force experience, be more educated and affluent as a group and be responsible for a household. In addition, families will be smaller, creating more pressure for individual older women to be selfsufficient for mobility and transportation needs. All of this will raise the demand for safe mobility and transportation access, and at least in the near future, lead to more use of automobiles.

3. For a given age, older women have more physical disability than men. However, this increased disablement is less associated with severe or fatal illnesses. Disability is complex and, in populations, may have diverse manifestations and differing effects on mobility and the selection of transportation modes. For example, difficulty in 
walking may lead to more automobile use and less use of public transportation such as urban buses, since getting to the bus stop may be difficult. On the other hand, dysfunctional vision or upper extremity use might have the reverse effect. Given the increasing number of older women and the net increase in those with various dysfunctions, the growing need for environmental modification of transportation modes seems obvious. As described in more detail below there is much more population information on the clinical aspects of physical disability than on mobility and functional transportation use.

4. The selection of and usage rates for various transportation modes is determined by many factors other than health status:

-Economic status is important. After holding health and social status constant, older women in the lowest quarter of family/personal wealth and assets have lesser ownership and use of automobiles, and lesser use of other modes of transportation. This is particularly true of impoverished and minority women. -Some research suggests that environment factors such as fear of crime and environmental pollution may affect driving and other transportation use rates. -Living in rural areas, where both public transportation and special transportation services for disabled persons are less available, may lead to diminished mobility among older women compared to their urban counterparts.

-Impediments to safe mobility are determined in part by urban, regional and residential design. Varying designs and architectural patterns may facilitate or deter meeting the social and other sustaining mobility needs of older women (e.g., visiting 
friends or the doctor, doing grocery shopping). Attention to these design issues will likely improve mobility for older women.

5. The automobile remains the dominant mode for transportation and mobility among older Americans, men and women, and according to national surveys, this dominance is increasing. The literature on driving cessation patterns among older women is incomplete but suggests that most give up driving based on a shared decision with family members, friends and health professionals. Cessation rates increase substantially after age 75 years. Only a very small proportion have driving privileges revoked by state transportation agencies. Older women drivers have lower crash rates than men and, on a per-mile-driven basis, rates remain among the lowest of any demographic group and do not increase much after age 60 years. Whether the increasing mobility needs and lesser availability of family members to provide transportation for older women in the future will lead to less cessation of driving and alter future crash rates is uncertain. This needs to be monitored.

Our overall conclusion is that there are vast needs for data, particularly on the national level, that are unmet. There are several reasons for this general need:

๘ There is no obvious or published documentation of the policy questions which national or regional surveys might address. This is not to criticize the large amount of useful research or problem identification, but data needs cannot be addressed in the absence of pre-specifying the issues to be addressed in suitable detail. 
๘ Much of the locally conducted research on the issues of older women's mobility, auto driving and transportation needs has not been reconciled or brought to sufficient national prominence.

ఐ Existing national or regional population-based surveys related to mobility and transportation have been quite useful, but have not contained a sufficient breadth of variables and information on the same individuals so that many of the important issues could be addressed in a comprehensive way.

$\varpi$ Existing surveys on geriatric and gerontological health status have a generally common way of collecting information of physical and psychological disability, but the items structures and formats are often not fully suitable for addressing transportation issues and the use of the automobile and other conveyances. More specific items, many of which have already been applied in surveys, need to be brought to bear on the questions of interest.

๗ It has been (understandably) difficult to link self-reported family and personal information related to mobility and transportation use to the health, transportation and other relevant data sources within and outside of government. This would greatly enhance the ability to understand many of the data-related issues that can't be obtained from personal self-report.

๘ The issues related to safe mobility among older women require a substantial number of disciplines: health and medicine, epidemiology and biostatistics, survey research, transportation engineering and design, human factors, social and behavioral science, etc. 
ఐ As far as we can tell, the demographic models employed mostly in the economics sphere have not been brought to bear on the mobility and transportation issues.

Solutions to these issues may be self-evident but execution of the solutions can be extremely difficulty. Thus, the following are a set of logistical and content

recommendations to address the data issues remaining and to supplement the existing and important data collection activities. It is appreciated that many of the recommendations below can be costly, and such research should be staged as resources permit. However, while acknowledging the large amount of skillful work that has been conducted to date, there are great gaps in our knowledge of transportation and mobility needs, and these gaps will be unfilled unless addressed aggressively.

A. At least one major national survey, or the upgrade of an existing survey, needs to be conducted at periodic intervals to assess the mobility issues of older women for purposes of planning and policy. While this is not the only mode of research needed, it will supply the data needs most quickly. It is not likely that existing surveys can serve as vehicles (i.e., "piggybacking") because the content will likely be too extensive to be shared with other content areas. The study should be a cohort study because some of the issues, such as determining risk factors for altered transportation use and the impact of changing health and economic status, can only be wellevaluated in longitudinal fashion.

B. Expert, multidisciplinary groups should be convened to determine the content of the surveys as well as the specific item structure. At a minimum, a committee structure to perform this activity should include the following disciplines: economics, law enforcement, insurance, transportation specialists for all the common types of 
conveyances, epidemiology, human factors, highway design and maintenance, social welfare, physical therapy, automotive medicine, rehabilitation medicine, recreation and leisure studies behavioral science, actuarial science (auto insurance), family economics and sociology, cognitive psychology, state-level transportation officials and urban and regional planning, with specialists in transportation.

C. Before decisions are made on survey content, focus groups and qualitative research should be conducted, building on existing work, to best understand the nature of the problems and develop a set of optimum solutions. For example, if a major barrier for lower SES women is the experience or fear of personal crime, then possible solutions will differ from those where the problem is lack of public transportation. At a minimum, there should be separate study of 1) various levels of urban and rural population density, 2) each of the major ethnic groups in the United States, including samples from areas with mixed ethnicity, 3) groups of varying economic means and 4) groups with varying environmental (contextual) factors, such as weather extremes and traffic density extremes. These groups can be dovetailed, where for example, rural areas are also the lower traffic density areas.

D. As the surveys are planned, consideration should also be given to conducting a set of concordant, targeted experiments to attempt to determine the range (particularly the maximal amount) of social mobility among older women with a standardized set of health characteristics. For example, it might be useful to randomize women of limited economic means who are not automobile operators to a large number of taxi vouchers per month for an extended period to see what the actual increment would be in availing oneself of this transportation access. While is not a reasonable population 
solution in the long term, it would possibly go a long way toward understanding the "real" outcomes of enhanced mobility.

E. Population surveys should contain a suitable set of cognitive and physical performance tests that build on past work funded by the USDOT and other agencies to determine and apply performance batteries that more closely evaluate the operation of automobiles as well the use of standard public transportation, in order to more accurately determine the population-level ability to operate or use various conveyances. Some additional considerations would be:

1. A set of "existing" gerontologically-applied physical function tests would still be necessary because of the ability of current, standardized measures to reflect and predict overall health status based on the wide variety of existing surveys. Additional analyses to map current gerontological function-status measures onto transportation-related measures would be extremely important.

2. Cognitive tests would need to be of sufficient sensitivity to determine the presence of levels of cognitive impairment or dementia that would lead to either unsafe auto operation or inability to safely use other conveyances.

3. As noted in the recommendation on focus groups above, there would likely be oversampling of various groups of older women in order to have desired statistical power. This might include oversampling of the oldest old, certain minority groups and those with certain illnesses known to put auto drivers at increased safety risk, such as diabetes, seizures and psychotropic medication consumption.

F. Participants in population surveys need to volunteer in advance to link personal data to other clinical and administrative data sources. These latter comprise sources of 
information for purposes of enhanced analysis and validation of self-report. In some instances, the information would not otherwise be obtainable, and would include: 1) all state information on licensure and reported crashes, 2) medical and related clinical information from the appropriate sources, including the Health Care Financing Administration (Medicare), hospitals and personal physicians and 3) the participants' insurance company, to understand the nature and activity of auto insurance policies.

G. Given the dominance of automobile travel for older women as well as all other demographic groups, there should be more detailed studies of the income/wealth and assets elasticity as a determinant of automobile ownership and use, as well as the use of other modes of transportation. Then, projections of personal and family wealth among older women can be applied more precisely to determine projected economic access to transportation. Older women in the lowest quartile of income seem to be most sensitive to maintaining auto ownership and use.

$\mathrm{H}$. In addition to population surveys, consideration should be given to surveys of providers of public and quasi-public transportation. It would seem of great use to document the problems and issues of older women's mobility as seen through the eyes of paratransit operators, bus drivers, taxi companies and other such operators. In addition, there is a source of transportation not well characterized at the present time on a population basis-the transportation provided by life care residential settings. More and more older women are living in guarded or elder-dedicated residential settings that supply transportation of varying levels of coverage and frequency that are not well-defined from a population perspective. This needs cataloging and registration because it appears to be a rapidly emerging source of mobility. 
I. A separate but growing issue is the increasing number of older women whose disability and mobility impairments were acquired in early or mid life. This may have been through developmental disabilities, disease, trauma or other causes. Their mobility desires and needs are all but totally unstudied, and there is a need for all types of qualitative and quantitative investigations to determine the types of transportation used and required, and the social settings in which they occur.

J. There is a need for further qualitative studies of the pathways to cessation of automobile driving by older women. While structured surveys can provide part of the answer, there is likely to be a rich and diverse set of circumstances that will not be captured that way. It is not merely the older woman driver who needs study; there should be interviews of other family members, physicians, friends, state officials and others who may have been involved in the decision-making activity.

$\mathrm{K}$. Long term studies of the city and regional planning methods that may promote improved mobility of older women need to be conducted. While there may be little quantification in this area, emerging ideas, trends in design and assessments of outcomes and implications need to be monitored. 


\section{Bibliography}

Administration on Aging. Meeting the Challenge: Mobility for Elders. Administration on Aging, Washington: December 1994.

Administration on Aging. National Eldercare Institute on Transportation Final Report. Administration on Aging, Washington: 1996.

Administration on Aging. The National Phone Conversations. Administration on Aging, Washington: October 1994.

Anderson RT. James MK. Miller ME. Worley AS. Longino CF Jr. "The timing of change: patterns in transitions in functional status among elderly persons." Journals of Gerontology. Series B, Psychological Sciences \& Social Sciences. 53(1):S17-27, 1998 Jan.

Atchley RC. The Social Forces in Later Life. Belmont, CA, Wadsworth: 1994.

Ball K. "Attentional problems and older drivers." Alzheimer Disease \& Associated Disorders. 11 Suppl 1:42-7, 1997 Jun.

Ball K. et al. "Driving Avoidance and Functional Impairment in Older Drivers" Accident Analysis \& Prevention. Vol. 30 No. 3 (1998) pp. 313-322.

Bianchi SM. Spain D. 1996. "Women, work, and family in America" Population Bulletin Vol. 51, No. 3. Washington, D.C.: Population Reference Bureau.

Barusch AS. Older Women in Poverty: Private Lives and Public Policies. New York, Springer Publishing Company: 1994.

Boult C. Kane RL. Boult L. McCaffrey D. "Chronic Conditions that Lead to Functional Limitation in the Elderly" Journal of Gerontology. Vol. 49 No. 1 (1994) pp. M28-M36.

Brainn PA. Safety and Mobility Issues in Licensing and Education of Older Drivers. US Department of Transportation National Highway Traffic Safety Administration, Publication DOT HS-7-01502, June 1980.

Buchner DM. "Preserving Mobility in Older Adults" WJM. Vol. 167 No. 4 (1997) pp. 258-264.

Bullard RD. Johnson GS. "Just Transportation." In Just Transportation, RD Bullard and GS Johnson, eds. New Society, Stony Creek, CT, 1997.

Burkhardt J. Berger AM. McGavock AT. "The Mobility Consequences of the Reduction or Cessation of Driving by Older Women" In Women's Travel Issues: Proceedings from 
the Second Conference. Federal Highway Administration Publication FHWA-PL-97024, pp. 439-454.

Centers for Disease Control and Prevention. "Mortality Patterns - United States, 1996." Morbidity and Mortality Weekly Report. 46 (40): 941-944, Oct. 101997.

Chipman ML. Payne J. McDonough P. "To Drive or Not to Drive: The Influence of Social Factors on the Decisions of Elderly Drivers" Accident Analysis \& Prevention. Vol. 30 No. 3 (1998) pp. 299-304.

Clark DO. Stump TE. Hui SL. Wolinsky FD. "Predictors of Mobility and Basic ADL Difficulty Among Adults Aged 70 Years and Older" Journal of Aging and Health. Vol. 10 No. 4 (1998) pp. 422-440.

Cornoni-Huntley J. Ostfeld AM. Taylor JO. Wallace RB. Blazer D. Berkman LF. Evans DA. Kohout FJ. Lemke JH. Scherr PA. et al. "Established populations for epidemiologic studies of the elderly: study design and methodology." Aging. 5(1):27-37, $1993 \mathrm{Feb}$.

Coughlin JF. Straight A. "Healthy Aging and Transportation Needs." Presented to The Older Driver, Health and Mobility, Trinity College Dublin. September 18-19, 1998.

Cox AB. Cox DJ. "Compensatory driving strategy of older people may increase driving risk [letter]." Journal of the American Geriatrics Society. 46(8):1058-9, 1998 Aug.

Crimmins EM. Saito Y. Reynolds SL. "Further evidence on recent trends in the prevalence and incidence of disability among older Americans from two sources: the LSOA and the NHIS." Journals of Gerontology. Series B, Psychological Sciences \& Social Sciences. 52(2):S59-71, 1997 Mar.

Doble SE. et al. "Measuring Functional Competence in Older Persons with Alzheimer's Disease." International Psychogeriatrics. 9 (1): 25-38, 1997.

Duke University Center for Demographic Studies. National Long-Term Care Survey, NLTCS Public Use Data, 1982, 1984, 1989, 1994. Durham, NC, 1998.

Dulisse B. "Older drivers and risk to other road users." Accident Analysis \& Prevention. 29(5):573-82, 1997 Sep.

Eberhard JW. "Safe Mobility for Senior Citizens" IATSS Research. Vol. 20 No. 1 (1996) pp. 29-37.

Edwards SD. "Dismantling the Disability/Handicap Distinction." The Journal of Medicine and Philosophy. 22:589-606, 1997. 
Evans L. Traffic Safety and the Driver. Van Nostrand Reinhold, New York: 1991. pp. $19-43$.

Foley D. Eberhard JW. Ostfeld AM. Wallace RB. deWolf V. "Design of a Driving Practices Survey in the Established Populations for Epidemiologic Studies of the Elderly." Presentation at the American Statistical Association 151st Annual Meeting, Anaheim, CA (1990).

Forrest KY. Bunker CH. Songer TJ. Coben JH. Cauley JA. "Driving patterns and medical conditions in older women." Journal of the American Geriatrics Society. 45(10):1214-8, 1997 Oct.

Fried LP. et al. "Physical Disability in Older Adults: A Physiological Approach" J Clin Epidemiol. Vol. 47 No. 7 (1994) pp. 747-760.

Galanos AN. Fillenbaum GG. Cohen HJ. Burchett BM. "The comprehensive assessment of community dwelling elderly: why functional status is not enough." Aging. 6(5):343-52, 1994 Oct.

Gauthier S. Gélinas I. Gauthier L. "Functional Disability in Alzheimer's Disease." International Psychogeriatrics. 9(1) Suppl.: 163-165, 1997.

Gonda J. "Transportation, Perceived Control, and Well-Being in the Elderly" Specialized Transportation Planning and Practice. Vol 1 (1982) pp. 61-72.

Gresset J. and Meyer F. "Risk of Automobile Accidents Among Elderly Drivers with Impairments or Chronic Diseases." Canadian Journal of Public Health. 85 (4): 282-285, 1994.

Guralnik et al. "Maintaining Mobility in Late Life." American Journal of Epidemiology. $137(8): 845-57,1993$.

Guralnik JM. Kaplan GA. "Predictors of healthy aging: prospective evidence from the Alameda County study." American Journal of Public Health. 79(6):703-8, 1989 Jun.

Hakamies-Blomqvist L. "Older Drivers' Accident Risk: Conceptual and Methodological Issues" Accident Analysis \& Prevention. Vol. 30 No. 3 (1998) pp. 293-298.

Hakamies-Blomqvist L. "Research on Older Drivers: A Review" IATSS Research. Vol. 20 No. 1 (1996) pp. 91-101.

Hakamies-Blomqvist L. "Why Do Older Drivers Give Up Driving?" Accident Analysis \& Prevention. Vol. 30 No. 3 (1998) pp. 305-312.

Hanson S. "Dimensions of the Urban Transportation Problem." In The Geography of Urban Transportation, S. Hanson, ed. The Guilford Press, New York, 1986. 
Harris T. Kovar MG. Suzman R. Kleinman JC. Feldman JJ. "Longitudinal study of physical ability in the oldest-old." American Journal of Public Health. 79(6):698-702, 1989 Jun.

Hu PS. Trumble DA. Foley DJ. Eberhard JW. Wallace RB. "Crash risks of older drivers: a panel data analysis." Accident Analysis \& Prevention. 30(5):569-81, 1998 Sep.

Hu PS. Trumble D. Lu A. Driving Decisions and Vehicle Crashes Among Older Drivers. Oak Ridge, Tennessee, Oak Ridge National Laboratory, June 1993.

Idler EL. Kasl SV. "Self-ratings of health: do they also predict change in functional ability?" Journals of Gerontology. Series B, Psychological Sciences \& Social Sciences. 50(6):S344-53, 1995 Nov.

Isler RB. Parsonson BS. Hansson GJ. "Age related effects of restricted head movements on the useful field of view of drivers." Accident Analysis \& Prevention. 29(6):793-801, 1997 Nov.

Janecek MJ. "Transportation as a Component in Rural Health Care Services" A Report on the Mini Conference on Aging and Transportation. National Eldercare Institute on Transportation and American Association of Retired Persons, July 1994.

Jette AM. "Disablement outcomes in geriatric rehabilitation." Medical Care. 35(6 Suppl):JS28-37; discussion JS38-44, 1997 Jun.

Jette AM. Branch LG. "A Ten-Year Follow-Up of Driving Patterns among the Community-Dwelling Elderly." Human Factors Vol. 34 No. 1 (1992) pp. 25-31.

Johansson K. Bronge L. Lundberg C. Persson A. Seideman M. Viitanen M. "Can a physician recognize an older driver with increased crash risk potential? Journal of the American Geriatrics Society. 44(10):1198-204, 1996 Oct.

Johnson JE. "Rural elders and the decision to stop driving." Journal of Community Health Nursing. 12(3):131-8, 1995.

Kandrack MA. Grant KR. Segall A. "Gender differences in health related behaviour: some unanswered questions." Social Science \& Medicine. 32(5):579-90, 1991.

Kaplan RM. Anderson JP. Wingard DL. "Gender Differences in Health-Related Quality of Life." Health Psychology. 10 (2): 86-93, 1991.

Kaye HS. Is the status of people with disabilities improving? Disability Statistics Abstracts \#21. Disability Statistics Center, Univ. of California San Francisco, May, 1998. 
Kington R. Reuben D. Rogowski J. Lillard L. "Sociodemographic and Health Factors in Drving Patterns after 50 years of age." American Journal of Public Health. 84(8): 13271329, 1994.

Klein BEK. Klein R. Lee KE. Cruickshanks KJ. "Performance-Based and Self-Assessed Measures of Visual Function as Related to History of Falls, Hip Fractures, and Measured Gait Time" Ophthmology. Vol. 105 No. 1 (1998) pp. 160-164.

Lawrence RH. Jette AM. "Disentangling the Disablement Process." Journals of Gerontology: Social Sciences. 48(4): 173-182, 1996.

Lundberg C. et al. "Dementia and driving: an attempt at consensus." Alzheimer Disease \& Associated Disorders. 11(1):28-37, 1997 Mar.

Lundberg C. Hakamies-Blomqvist L. Almkvist O. Johansson K. "Impairments of some cognitive functions are common in crash-involved older drivers. "Accident Analysis \& Prevention. 30(3):371-7, 1998 May.

Manton KG. Corder L. Stallard E. "Chronic disability trends in elderly United States populations: 1982-1994." Proceedings of the National Academy of Sciences of the United States of America. 94(6):2593-8, 1997 Mar 18.

Manton KG. "Demographic Trends for the Aging Female Population." Journal of the American Medical Women's Association. 52 (3): 99-105, 1997.

Manton KG. Stallard E. Corder LS. "The dynamics of dimensions of age-related disability 1982 to 1994 in the U.S. elderly population." Journals of Gerontology. Series A, Biological Sciences \& Medical Sciences. 53(1):B59-70, 1998 Jan.

Manton KG. "A longitudinal study of functional change and mortality in the United States." Journal of Gerontology. 43(5):S153-61, 1988 Sep.

Marottoli RA. Ostfeld AM. Merill SS. Perlman GD. Foley DJ. Cooney LM. "Driving Cessation and Changes in Mileage Driven Among Elderly Individuals." Journal of Gerontology: Social Sciences. 48(5):77-81, 1993.

Marottoli RA. Mendes de Leon CF. Glass TA. Williams CS. Cooney LM Jr. Berkman LF. Tinetti ME. "Driving cessation and increased depressive symptoms: prospective evidence from the New Haven EPESE. Established Populations for Epidemiologic Studies of the Elderly." Journal of the American Geriatrics Society. 45(2):202-6, 1997 Feb.

Marottoli RA. Richardson ED. "Confidence in, and Self-Rating of, Driving Ability Among Older Drivers" Accident Analysis \& Prevention. Vol. 30 No. 3 (1998) pp. 331336. 
Martinez R. “Older drivers and physicians.” JAMA. 274(13):1060, 1995 Oct 4.

McGrane, J. "The Perspective of the Transportation Provider" A Report on the Mini Conference on Aging and Transportation. National Eldercare Institute on Transportation and American Association of Retired Persons, July 1994.

Merrill SS. Seeman TE. Kasl SV. Berkman LF. "Gender differences in the comparison of self-reported disability and performance measures." Journals of Gerontology. Series A, Biological Sciences \& Medical Sciences. 52(1):M19-26, 1997 Jan.

Mor V. Murphy J. Masterson-Allen S. Willey C. Razmpour A. Jackson ME. Greer D. Katz S. "Risk of functional decline among well elders." Journal of Clinical Epidemiology. 42(9):895-904, 1989.

Morgan R. King D. "The older driver - a review." Postgraduate Medical Journal. 71(839):525-8, 1995 Sep.

Muller PO. "Transportation and Urban Form: Stages and Spatial Evolution of the American Metropolis." In The Geography of Urban Transportation, S. Hanson, ed. The Guilford Press, New York, 1986.

Murray SL. "Driving and the elderly." Journal of the American Academy of Nurse Practitioners. 9(3):133-6, 1997 Mar.

Oldenheimer GL. "Dementia and the Older Driver." Clinics in Geriatric Medicine. 9(2):349-358, 1993.

Owsley C. Ball K. McGwin G Jr. Sloane ME. Roenker DL. White MF. Overley ET. "Visual processing impairment and risk of motor vehicle crash among older adults. JAMA. 279(14):1083-8, 1998 Apr 8.

Penning MJ. Strain LA. "Gender Differences in Disability, Assistance, and Subjunctive Well-Being in Later Life." Journals of Gerontology: Social Sciences. 49 (4): S202S208, 1994.

Perryman KM. Fitten LJ. "Effects of normal aging on the performance of motor-vehicle operational skills." Journal of Geriatric Psychiatry \& Neurology. 9(3):136-4l, 1996 Jul.

Pinsky JL. Leaverton PE. Stokes J 3d. "Predictors of good function: the Framingham Study." Journal of Chronic Diseases. 40 Suppl 1:159S-167S, 181S-2, 1987.

Purvis CL. San Francisco Bay Area 1990 Regional Travel Characteristics: Working Paper \#4. Planning Section, Metropolitan Transportation Commission: December 1994. 
Rabbitt P. Carmichael A. Jones S. Holland C. When and Why Older Drivers Give Up Driving. AA Foundation for Road Safety Research Age and Cognitive Research Centre, Manchester: 1996.

Retchin SM. Anapolle J. "An overview of the older driver." Clinics in Geriatric Medicine. 9(2): 279-295, May 1993.

Rodgers W. Miller B. "A comparative analysis of ADL questions in surveys of older people." Journals of Gerontology. Series B, Psychological Sciences \& Social Sciences. 52 Spec No:21-36, 1997 May.

Rosenbloon S. "Transportation Needs of the Elderly Population" Clinics in Geriatric Medicine. Vol. 9, No. 2 (1993) pp. 297-310.

Rosenbloom S. "The Travel Patterns of Elderly Women Alone: A Research Note" Specialized Transportation and Practices. Vol. 3 (1989) pp. 295-309.

Schieber F. "High-Priority Research and Development Needs for Maintaining the Safety and Mobility of Older Drivers." Experimental Aging Research. 20: 35-43, 1994.

Schoeffler LE. "Eyesight and the elderly." Oklahoma State Medical Association. 89(10):379, 1996 Oct.

Sims RV. Owsley C. Allman RM. Ball K. Smoot TM. "A preliminary assessment of the medical and functional factors associated with vehicle crashes by older adults." Journal of the American Geriatrics Society. 46(5):556-61, 1998 May.

Stamatiadis N. "Elderly Male and Female Drivers: How Different Are They?" Washington, DC, Transportation Research Board, from January 10-14, 1993, annual meeting.

Stamatiadis N. Deacon JA. "Trends in highway safety: effects of an aging population on accident propensity." Accident Analysis \& Prevention. 27(4):443-59, 1995 Aug.

Strahan RF. Mercier CR. Mercier JM. O'Boyle MW. "Personality structure of elderly drivers." Perceptual \& Motor Skills. 85(2):747-55, 1997 Oct.

Stutts JC. "Do older drivers with visual and cognitive impairments drive less?." Journal of the American Geriatrics Society. 46(7):854-61, 1998 Jul.

Thomas VS. Rockwood K. McDowell I. "Multidimensionality in Instrumental and Basic Activities of Daily Living" J Clin Epidemiol. Vol. 51 No. 4 (1998) pp. 315-321.

US Department of Health and Human Services, Public Health Service, Centers for Disease Control and Prevention, National Center for Health Statistics. The Longitudinal Study of Aging, 1984-90 computer file. SETS version 1.21. Hyattsville, Md., 1993. 
US Department of Health and Human Services, Public Health Service, National Institutes of Health. Established Populations for Epidemiologic Studies of the Elderly: Resource Data Book. Bethesda, Md.,1986.

US Department of Transportation. The National Highway Traffic Safety Administration's Traffic Safety Plan for Older Persons. US Department of Transportation, DOT HS-807316, September 1988.

US Department of Transportation Bureau of Transportation Statistics. 1995 Nation's Travel: Early Results from the 1995 Nationwide Personal Travel Survey.

Veevers J. "Women in the Driver's Seat: Trends in Sex Differences in Driving and Death." Population Research and Policy Review. Vol. 1 (1982) pp. 171-182.

Verbrugge LM. Jette AM. “The disablement process." Social Science \& Medicine. 38(1):1-14, 1994 Jan.

Verbrugge LM. "Longer life but worsening health? Trends in health and mortality of middle-aged and older persons." Milbank Memorial Fund Quarterly - Health \& Society. 62(3):475-519, 1984.

Verbrugge LM. "Multiple roles and physical health of women and men." Journal of Health \& Social Behavior. 24(1):16-30, 1983 Mar.

Verbrugge LM. Reoma JM. Gruber-Baldini AL. "Short-term dynamics of disability and well-being." Journal of Health \& Social Behavior. 35(2):97-117, 1994 Jun.

Wallace RB. "The search to improve safe vehicular operation among older drivers: are we reaching our destination? [editorial]." Journal of the American Geriatrics Society. 46(5):652-3, 1998 May.

Warnes AM. Fraser DA. "Car Driving as a Social Skill." In Geragogics: European Research. The Haworth Press, 1992.

Weaver P. "Elder Mobility: Transportation Policy and Research Issues as We Move Towards the 21st Century" presented at the Mini-White House Conference on Aging and Transportation., Pittsburgh, Pennsylvania, May 24, 1994.

Wingard DL. "The Sex Differential in Morbidity, Mortality, and Lifestyle." American Review of Public Health. 5:433-58, 1984.

Winter SE. "Effects of Driving Cessation on the Older Adult." California State University Sacramento (1996), Master of Arts in Psychology Thesis. 
Wiseman EJ. Souder E. "The older driver: a handy tool to assess competence behind the wheel." Geriatrics. 51(7):36-8, 41-2, 45, 1996 Jul.

World Health Organization. International Classification of Impairment, Disabilities and Handicaps. WHO, Geneva, 1993. 


\section{Appendix \\ Assessment of Existing Geriatric and Social/Economic Surveys Relevant to the Safe Mobility of Older Women}

AA Foundation for Road Safety Research Age and Cognitive Centre Study

Aging in the Eighties: America in Transition

Assets and Health Dynamics Among the Oldest-Old [AHEAD]

Beaver Dam Eye Study

Established Populations for Epidemiologic Studies of the Elderly [EPESE]

Fatality Analysis Reporting System [FARS]

General Social Surveys

Health and Nutrition Examination Survey [NHANES]

Health and Retirement Study [HRS]

Human Aging: A Biological and Behavioral Longitudinal Study of Males

Informal and Formal Supports in Aging

Intergenerational Study of Parents and Children: 1962-1993

Iowa $65+$ Rural Health Study

Longitudinal Study of Aging [LSOA] and Supplemental on Aging II [SOA II]

Massachusetts Health Care Panel Study

National Health Interview Survey of Disability

National Long-Term Care Survey [NLTCS] 
National Survey of Families and Households

National Survey of Functional Health Status

National Survey of Problems Facing Elderly Americans Alone

Nationwide Personal Transportation Survey

San Francisco Bay Area Regional Travel Study

Time Use Longitudinal Study

Wisconsin Longitudinal Survey [WLS] 


\section{AA Foundation for Road Safety Research Age and Cognitive Centre Survey}

Populations: 2134 individuals (1156 men and 963 women) aged 55 to 101 from the University of Manchester's Longitudinal Age Research volunteer panel.

Study design: Questionnaire on past experience and future experience of driving sent with abbreviated version of the Cornell Medical Index

Relevant Dates: 1992-1994

Type of health and functional data: Abbreviated version of the Cornell Medical Index

Mobility and transportation data: Driving history, thoughts of giving up driving in the future or reasons for having given up driving, current driving habits, responses to proposals and sanctions to increase safety for older drivers

Gender difference data: Data stratified by gender

General findings: Continued driving is associated with higher SES and lower Cornell Medical Index scores. Although the largest concern of both current drivers and former drivers is the loss of mobility that giving up driving would result, many former drivers have adapted well to alternative modes of mobility. Even so, over $50 \%$ of former drivers feel that public transportation is not adequate.

About one-third of current drivers say they intend to continue to drive until an unforeseen event forces them to cease driving, and they differ from current drivers who are willing to estimate a particular date for driving cessation in that those who continue to carry on driving are more confident in their driving ability and rely on the automobile more.

Although over $20 \%$ of ex-drivers reported loss of driving competence, less than $4 \%$ of those still driving reported noticing a decrease in driving competence in any of 14 categories.

Weakness with respect to the junction of issues of women, mobility, transportation and health: The AA Foundation study directly addresses issues of mobility, transportation and health, but its direct application to the American elder transportation situation must be questioned. In addition, because the questionnaire was not tailored directly to the needs of women, elder women's issues may be neglected. 


\section{Assets and Health Dynamics Among the Oldest-Old [AHEAD]}

HRS Auxiliary Study

Populations: National panel study of cohorts born 1923 and earlier, 7447 respondents aged $70+$ (including 2548 aged 80 and over) plus 775 younger spouses with oversamples of blacks, Hispanics and Florida residents

Relevant Dates: Wave 1 data collection completed in February 1994, Wave 2 completed in May 1996, Wave 3 data collection February-October 1998

Type of health and functional data: Detailed data on health conditions, cognition (and proxy cognition), health care and health care costs, job status, time use and expectations of the future

Mobility and transportation data: No direct data collection on these issues, to be linked with ADL data in LSOA2 and NLTCS

Gender difference data: Stratified by gender

General findings: Information on the economic and family issues surrounding late-life health

Weakness with respect to the junction of issues of women, mobility, transportation and health: AHEAD provides value in assessing the health changes in elders, especially in linkage with mobility-specific data 


\section{Beaver Dam Eye Study}

Populations: An initial cohort of 5924 from Beaver Dam, Wisconsin, of persons aged 43 to 84 years was identified from September 1987 to May 1988 and given a baseline visual examination. A follow-up examination was given from March 1992 through June 1995.

Type of health and functional data: Detailed data on visual acuity, contrast sensitivity, visual sensitivity and ambulation was determined. The participants were questioned on falls and fractures after age 40 .

Gender difference data: Stratified by gender

General findings: Lower visual functioning was associated with gait time, and this suggests that visual functioning affects later-life mobility.

Weakness with respect to the junction of issues of women, mobility, transportation and heaith: The Beaver Dam Eye Study is a regional study that has as its focus visual functioning and its direct implications on ambulation, which may be of use as a proxy for the implications of visual functioning on community mobility and transportation. 


\section{Established Populations for Epidemiologic Studies of the Elderly [EPESE]}

Populations: 14,000 persons in four geographically-defined communities in East Boston, Massachusetts; Iowa and Washington Counties, Iowa; New Haven, Connecticut; and in a five county-wide region in north-central North Carolina.

Relevant Dates: Data collection 1981-1992 in Massachusetts and Iowa, 1982-present in Connecticut, 1986-present in North Carolina

Study design: Baseline and annual follow-up surveys

Type of health and functional data: Demographic characteristics, social and physical functioning, health service utilization

Mobility and transportation data: Automobile driving data from Iowa 65+ Rural Health Study, other proxy data for mobility from ADL and social interaction questionnaire topics

Gender difference data: Data stratified by gender

Weakness with respect to the junction of issues of women, mobility, transportation and health: Mobility issues not central in all four geographic areas of the EPESE 


\section{Fatality Analysis Reporting System [FARS]}

Populations: All crashes involving a fatality (either motorist or non-motorist) as reported by each US state transportation department

Relevant Dates: Yearly since 1975

Type of health and functional data: None

Mobility and transportation data: Specifics (age of participants, gender, posted speed limit, number and type of car involved, time of day) on accident

Weakness with respect to the junction of issues of women, mobility, transportation and health: The Fatality Analysis Reporting System is limited in its use to determining the specifics of health, transportation and mobility in elder women 


\section{General Social Surveys [GSS]}

Populations: A total of 32,380 completed interviews

Relevant Dates: Conducted during February, March, and April of 1972, 1973, 1974, 1975, 1976, 1977, 1978, 1980, 1982, 1983, 1984, 1985, 1986, 1987, 1988, 1989, 1990, 1991,1993 and 1994.

Study design: Random sampling of US population and telephone interviews of approximately one and a half hours in length

Type of health and functional data: Detailed questions on health and ADL functioning disabilities

Mobility and transportation data: Community assistance

Weakness with respect to the junction of issues of women, mobility, transportation and health: This nationwide survey is broad enough in scope both to address a wide range social and community issues for elder mobility (that may not be considered elsewhere) and to limit its focus in any one area 


\section{Health and Nutrition Examination Survey [NHANES]}

Populations: 18,447 interviewed persons $12-74$ years of age

Relevant Dates: $1976-1980$

Study design: 25,286 were interviewed and 20,322 were medically examined $(4,964$ individuals were interviewed but not examined)

Type of health and functional data: The medical histories include items on medication, hospital care, tuberculosis, a variety of acute and chronic diseases, tobacco usage, physical activity, weight, height, vision disability, exposure to pesticides, gastrointestinal problems and, for females, a menstrual and pregnancy history.

Mobility and transportation data: Not included

Weakness with respect to the junction of issues of women, mobility, transportation and health: Provides baseline health data for a broad sample of the older population 


\section{Health and Retirement Study [HRS]}

Populations: Initial sample of 7600 households, national panel study of respondents from 1931-41 birth cohort, oversamples of Hispanics, blacks and Florida residents

Study design: Baseline in-home face-to-face interviews in 1992 for 1931-41 birth cohort and in 1998 for 1924-30 and 1942-47 birth cohorts

Mail follow-ups every second year and proxy interviews after death

Type of health and functional data: Detailed data on health conditions, cognition (and proxy cognition), health care and health care costs, job status, time use and expectations of the future

Mobility and transportation data: No direct data collection on these issues, experimental modules on functional health, ADLs, activities and time allocation

Gender difference data: Stratified by gender

General findings: Information on the economic and family issues surrounding late-life health

Weakness with respect to the junction of issues of women, mobility, transportation and health: HRS provides value in assessing the health changes in elders, especially in linkage with mobility-specific data 


\section{Human Aging: A Biological and Behavioral Longitudinal Study of Males}

Populations: The basic design of the study involved the observation and examination, in 1957, of a group of 47 aged men (ranging in age from 65 to 92 years) who were in good health. Five years later a follow-up study was planned for the 39 men still alive. However, only 29 of the 39 men could be located and persuaded to return for further testing. The second follow-up, done in 1968, involved 19 of the surviving 23 men. The study was supported by grants from the National Institute of Mental Health. The data are arranged in files by year: 1957, 1962, and 1968. Included are psychiatric data, medical evaluative data, biographical and demographic variables, and various psychological and medical test scores. There are approximately 1,800 variables and 2,400 card-image equivalents.

Type of health and functional data: Comprehensive micro-view of health, aging and functioning

Weakness with respect to the junction of issues of women, mobility, transportation and health: While not focusing on population-based measures of gender, mobility and health, the Human Aging study provides and baseline view of aging and its concurrent physiological and mental changes 


\section{Informal and Formal Supports in Aging}

Populations: 1431 noninstitutionalized persons aged 40 and older living in three New York counties: Albany, Rensselaer and Schenectady

Study type: Personal interview

Relevant Dates: September 1988-February 1989

Type of health and functional data: Basic ADLs, data on household chores performed, variables on family relationships and social support networks

Mobility and transportation data: Ability to perform activities in the community alone and with the assistance of family and other social support networks

Gender difference data: Data stratified by gender

Weakness with respect to the junction of issues of women, mobility, transportation and health: Regional in nature 


\section{Intergenerational Study of Parents and Children: 1962-1993}

Populations: 2127 Detroit-area Caucasian families who had given birth to their first, second or fourth child in 1961

Relevant Dates: Initial in-person interviews in 1962 with mothers; follow-up interviews with mothers in 1963, 1966, 1977, 1980, 1985 and 1993; follow-up interviews with children in 1977, 1980, 1985 and 1993

Type of health and functional data: Behavioral, social and cross-generational transfer data

Mobility and transportation data: Social

Gender difference data: Focus on suburban mothers' social changes through time

Weakness with respect to the junction of issues of women, mobility, transportation and health: Provides only an oblique view of female mobility and health for a regional cohort 


\section{Iowa 65+ Rural Health Study}

Populations: 3762 persons 65 and over in 1981, the date of the initial interview, in Iowa and Washington counties in rural Iowa

Relevant Dates: Baseline survey between December 1991 and August 1982 with inperson follow-up surveys 3,6 and 10 years after baseline and $1,2,4,5$ and 7 years after baseline

Type of health and functional data: Major health conditions, nutrition, cognitive performance, activities of daily living, NIA-MacArthur Battery tests for physical performance, medical care utilization from the HCFA

Mobility and transportation data: Social networks and support, automobile driving habits, linked to Iowa state driving records

Gender difference data: Stratified by gender 


\section{Longitudinal Study of Aging [LSOA] and Supplemental on Aging II [SOA II]}

Populations: 16148 persons aged 55 and over interviewed during the 1984 National Health Interview Survey formed the Supplement on Aging (SOA). The 1984 SOA formed the baseline for the Longitudinal Study of Aging (LSOA), which followed those 70 and over through telephone follow-up interviews in 1986,1988 and 1990. A sample of 9447 persons aged 70 and over formed the second Supplement on Aging (SOA II) as part of the 1994 National Health Interview Survey. A second Longitudinal Study of Aging (LSOA II) will be conducted with the first follow-up interview conducted in 1997.

Type of health and functional data: Health conditions and impairments, linkage to HCFA Medicare records, the National Death Index, functional status

Mobility and transportation data: Transportation use, assistance with basic activities, social contracts, use of community services

Weakness with respect to the junction of issues of women, mobility, transportation and health: Although a fully national sample, this data does not directly address the mobility needs of female elders, especially community mobility in terms of automobile use 


\section{Massachusetts Health Care Panel Study}

Populations: 1625 community-dwelling Massachusetts residents aged 65 and older

Relevant Dates: Baseline questionnaires in 1974-75 with reinterviews at 1.25 years, 6 years and 10 years

Type of health and functional data: General self-reported health status and DALYs data collected

Mobility and transportation data: Detailed mobility pattern data (trip typing, social mobility reliance

Gender difference data: Data stratified by gender

General findings: Although self-regulation appears to be the major influence on elder's continued driving, continued reliance on driving is not closely related to an elder's health status.

Weakness with respect to the junction of issues of women, mobility, transportation and health: Regional in nature, the Massachusetts Health Care Panel Study is general in nature and does not directly focus on women and relies on only general self-reported health status measures 


\section{National Health Interview Survey of Disability, 1994: Phase II Adult Followback}

Populations: 16114 adults interviewed nationwide during the 1994 National Health Interview Survey

Study design: The National Health Interview Survey on Disability (NHIS-D), Phase II, was administered at the same time as the NHIS 1994 core, NATIONAL HEALTH INTERVIEW SURVEY, 1994. This questionnaire collected basic data on disability and was used as a screening device to determine eligibility for the second phase of the survey, the NHIS-D Disability Followback Survey.

Type of health and functional data: Detailed data on disability types, especially on non-end of life disabilities

Mobility and transportation data: Data on driving and other community transportation

Weakness with respect to the junction of issues of women, mobility, transportation and health: Focus of National Health Interview Survey on Disability not particularly on older persons, and thus the sample size is relatively small. However, there is enough detail for population estimates and for approaching some of the time mobility issues. 


\section{National Long-Term Care Survey [NLTCS]}

Populations: A national sample taken from Medicare beneficiary enrollment files

Sample design: The initial 1982 NLTCS was a sample of 35,008 persons, of which 6,393 were found to have at least one chronic impairment in the seven Instrumental Activities of Daily Living or nine Activities of Daily Living. This group was interviewed at home for data on health, functioning and other issues.

The 1984 NLTCS followed the 1982 cohort and $45 \%$ of the non-disabled 1982 population was rescreened for newly emergent chronic disability. In addition, a sample of individuals who became 65 since 1982 was screened for disability.

The 1989 NLTCS followed the 1982 and 1984 disabled cohorts and rescreened portions of the non-chronically disabled from the 1982 and 1984 samples. In addition, persons from the 1984 sample who had reached 75 years by 1989 were automatically rescreened.

The 1994 NLTCS followed the earlier cohorts, added a new sample of those reaching 65 since 1989 and rescreened non-chronically disabled members of the earlier cohorts.

Type of health and functional data: $A D L$ and $I A D L$ assessment and general health conditions data collected, linkage with Medicare Part A and Part B from 1982 to 1995

Mobility and transportation data: Not assessed

Gender difference data: Data stratified by gender

Weakness with respect to the junction of issues of women, mobility, transportation and health: This national sample bears witness to the function of disability in respect to functional disability, but the NLTCS was not designed to focus on mobility 


\section{National Survey of Families and Households}

Populations: National sample of 13000

Relevant Dates: A baseline questionnaire in 1987-88 with face-to-face reinterviews in 1992-94

Type of health and functional data: Health, well-being, DALYs and intergenerational assistance data

Weakness with respect to the junction of issues of women, mobility, transportation and health: May provide national baseline measures for intergenerational assistance that may reflect mobility assistance 


\section{National Survey of Functional Health Status}

Populations: The sample frame for the NHS included 1,537 GSS households from 1989 and 1,372 GSS households from the 1990 GSS for a total base sample of 2,909 households Second, the NHS selected for interview 342 elderly persons who were residing in the target households but had not been selected for GSS interviews.

Relevant Dates: 1990

Type of health and functional data: Assessment of ADL functioning and health status with particular emphasis on how these factors affect elder's perceived well-being

Mobility and transportation data: Data on how mobility functioning affects elder's quality of life

Weakness with respect to the junction of issues of women, mobility, transportation and health: Although the National Survey of Functional Health addresses the intersection of aging, health and physical functioning, its focus is on quality of life and basic ADLs rather than the ability of elder females to drive and maintain community mobility 


\section{National Survey of Problems Facing Elderly Americans Alone}

Populations: 2002 persons aged 65 and over, weighted by sex, age, race, education and living arrangement with an oversample of 504 additional persons aged 75 and over

Relevant Dates: June 11-July 311986

Study type: Random digit dialing of 23,000 telephone numbers nationwide

Type of health and functional data: Self-reported ADLs, health status, cognitive assessment and types of assistance respondents reported receiving from family and the community

Mobility and transportation data: General questions on community mobility

Gender difference data: No specific interview topics based on respondent's gender

Weakness with respect to the junction of issues of women, mobility, transportation and health: The National Survey of Problems Facing Elderly Americans Alone provides a baseline measure of the social aspects of elder life without focusing specifically on mobility or elder females 


\section{Nationwide Personal Transportation Survey}

Populations: 95360 person in 42033 households nationwide contacted through random digit dialing

Relevant Dates: 1995 with similar studies conducted in 1983, 1977 and 1969

Type of health and functional data: Age, SES, weight and general functional health status ascertained

Mobility and transportation data: Daily trip logs fully detailing all personal trips (long and within the community) by each mode of transportation

Gender difference data: Data stratified by age and gender

General findings: Research based on the NPTS has suggested that aging female baby boomers are more likely to drive into late-life than earlier generations of elder females

Weakness with respect to the junction of issues of women, mobility, transportation and health: The data is quite general in terms of health status and does not directly address the mobility issues of elder females 


\section{San Francisco Bay Area Regional Travel Study}

Populations: Telephone travel survey of 10838 San Francisco Bay Area residents

Relevant Dates: 1990 with additional survey data from 1981 and 1965

Type of health and functional data: General mobility-related data on difficulty of walking, driving and use of public transportation

Mobility and transportation data: Detailed travel log data for three day period

Weakness with respect to the junction of issues of women, mobility, transportation and health: A regional sample that does not health and disability data with mobility questions 


\section{Time Use Longitudinal Study}

Populations: This combined data collection consists of data from 620 respondents, their spouses if they were married at the time of first contact, and up to three children between the ages of three and seventeen living in the household.

Study design: The key features which characterized the 1975 time use study were repeated in 1981. In both of the data collection years, adult individuals provided four time diaries as well as extensive information related to their time use in the four waves of data collection. Information pertaining to the household was collected, as well as identical measures from respondents and spouses for all person-specific information. Selected children provided two time diary reports (one for a school day and one non-school day), an academic achievement measure, and survey measures pertaining to school and family life. In addition, teacher ratings were obtained. For each adult individual who remained in the sample through the 1981 study, a time budget was constructed from his or her time diaries containing the number of minutes per week spent in each of some 223 mutually exclusive and exhaustive activities. These measures provide a description of how the sample individuals were currently allocating their time and are comparable to the 87 activity measures created from their 1975 diaries. In addition, respondent and spouse time aggregates were converted to parent time aggregates for mothers and fathers of children in the sample. To facilitate analyses on spouses, a merged data file was created for 868 couples in which both husband and wife had complete Wave I data in either 1975-1976 or 1981.

Weakness with respect to the junction of issues of women, mobility, transportation and health: While this study does not focus on health or transportation issues, the Time Use Longitudinal Study may provide basic sociological background data for researchers interested in the integration of transportation and mobility in elders' lives. 


\section{Wisconsin Longitudinal Survey [WLS]}

Populations: Cohort of 10317 persons who graduated from Wisconsin high schools in 1957

Relevant Dates: Data collected from the cohort or their parents in 1957, 1964, 1975 and 1992 and from a sibling in 1977 and 1993

Type of health and functional data: Health and physical functioning self-reported assessment, caregiving received or given, social and family relationships

Mobility and transportation data: No data specific to transportation

Weakness with respect to the junction of issues of women, mobility, transportation and health: The Wisconsin Longitudinal Survey is a regional tool that focuses on neither mobility nor health status change, but does provide a long-term continuous cohort of an aging population 
DOT HS 808949

August 1999

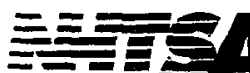

People saving People

winduteadotgor 